OPEN ACCESS

Edited by:

Milya Davlieva,

Quantapore, United States

Reviewed by:

Sandeep Kaur,

Mehr Chand Mahajan DAV College

for Women Chandigarh, India

Edmondo Campisi,

The Rockefeller University,

United States

*Correspondence:

R. Paul Ross

p.ross@ucc.ie

Specialty section:

This article was submitted to

Molecular Diagnostics

and Therapeutics,

a section of the journal

Frontiers in Molecular Biosciences

Received: 15 January 2021

Accepted: 07 April 2021

Published: 29 April 2021

Citation:

Walsh L, Johnson CN, Hill C and Ross RP (2021) Efficacy of Phageand Bacteriocin-Based Therapies in Combatting Nosocomial MRSA

Infections.

Front. Mol. Biosci. 8:654038. doi: 10.3389/fmolb.2021.654038

\section{Efficacy of Phage- and Bacteriocin-Based Therapies in Combatting Nosocomial MRSA Infections}

\author{
Lauren Walsh',2, Crystal N. Johnson 1,2,3, Colin Hill1,2 and R. Paul Ross ${ }^{1,2,3 *}$ \\ 1 School of Microbiology, University College Cork, Cork, Ireland, ${ }^{2}$ APC Microbiome Ireland, University College Cork, Cork, \\ Ireland, ${ }^{3}$ Teagasc Food Research Centre, Moorepark, Cork, Ireland
}

Staphylococcus aureus is a pathogen commonly found in nosocomial environments where infections can easily spread - especially given the reduced immune response of patients and large overlap between personnel in charge of their care. Although antibiotics are available to treat nosocomial infections, the increased occurrence of antibiotic resistance has rendered many treatments ineffective. Such is the case for methicillin resistant $S$. aureus (MRSA), which has continued to be a threat to public health since its emergence. For this reason, alternative treatment technologies utilizing antimicrobials such as bacteriocins, bacteriophages (phages) and phage endolysins are being developed. These antimicrobials provide an advantage over antibiotics in that many have narrow inhibition spectra, enabling treatments to be selected based on the target (pathogenic) bacterium while allowing for survival of commensal bacteria and thus avoiding collateral damage to the microbiome. Bacterial resistance to these treatments occurs less frequently than with antibiotics, particularly in circumstances where combinatory antimicrobial therapies are used. Phage therapy has been well established in Eastern Europe as an effective treatment against bacterial infections. While there are no Randomized Clinical Trials (RCTs) to our knowledge examining phage treatment of $S$. aureus infections that have completed all trial phases, numerous clinical trials are underway, and several commercial phage preparations are currently available to treat $S$. aureus infections. Bacteriocins have primarily been used in the food industry for bio-preservation applications. However, the idea of repurposing bacteriocins for human health is an attractive one considering their efficacy against many bacterial pathogens. There are concerns about the ability of bacteriocins to survive the gastrointestinal tract given their proteinaceous nature, however, this obstacle may be overcome by altering the administration route of the therapy through encapsulation, or by bioengineering protease-resistant variants. Obstacles such as enzymatic digestion are less of an issue for topical/local administration, for example, application to the surface of the skin. Bacteriocins have also shown impressive synergistic effects when used in conjunction with other antimicrobials, including antibiotics, which may allow antibiotic-based therapies to be used more sparingly with less resistance development. 
This review provides an updated account of known bacteriocins, phages and phage endolysins which have demonstrated an impressive ability to kill S. aureus strains. In particular, examples of antimicrobials with the ability to target MRSA strains and their subsequent use in a clinical setting are outlined.

Keywords: bacteriophage, endolysins, bacteriocins, MRSA, nosocomial environment

\section{INTRODUCTION}

The current COVID-19 pandemic has revealed just how vulnerable humankind is to infectious agents where natural selection and mutations give rise to new pathogens for which we have few to no therapeutic solutions. Antimicrobial resistance (AMR) is another global public health crisis exacerbated by the lack of discovery of novel antibiotic agents and absence of investment and innovation in pipelines by the pharmaceutical industry. Staphylococcus aureus infections can cause a range of ailments from skin conditions to potentially fatal diseases such as invasive endocarditis and sepsis (Lowy, 1998; Chambers, 2001). The emergence of antibiotic resistant bacteria began with penicillin resistant S. aureus (Enright et al., 2002). This threat was more or less overcome by the introduction of additional, antibiotics, such as methicillin, as alternative therapeutics to combat penicillin resistant $S$. aureus. However, following 2 years of successful treatment, methicillin resistant $S$. aureus (MRSA) emerged and has since developed into a global crisis (Enright et al., 2002). Indeed, antimicrobial resistance is a significant threat to the health of the human population, with predictions that by 2050 antimicrobial resistance will claim 10 million deaths per year (Hu et al., 2020). Antibiotic resistance not only has dire consequences for health but also increases costs associated with healthcare (European Centre for Disease Prevention and Control [ECDC], 2014) and has downstream consequences for the environment and economy.

Methicillin resistant $S$. aureus specifically has become a pathogen commonly found in nosocomial environments (Tiemersma et al., 2004; Weiner-Lastinger et al., 2020). Although medical devices and commonly used surfaces may mediate the transfer of MRSA, the primary vectors of transmission of MRSA are the patients themselves and the personnel they contact. In clinical environments, ointment containing the antibiotic mupirocin is commonly used to eradicate staphylococcal nasal carriage. While this type of therapeutic has been shown as an effective form of prevention and treatment, resistance does develop (Fenton et al., 2010a). Vancomycin is also a commonly used antibiotic to treat MRSA infection, however, vancomycin resistant S. aureus (VRSA) has now also become a prominent issue in the nosocomial environment (Horne et al., 2009). New antibiotics are being developed to fight against MRSA infection, such as ceftaroline which has been commercially available since 2012. Numerous other antibiotics have undergone phase III clinical trials including dalbavancin (NCT01339091), oritavancin (NCT01252719) and nemonoxacin (NCT02205112) (Table 1) (Pasberg-Gauhl, 2014). Although new antibiotics are being developed their susceptibility to bacterial resistance still remains a substantial problem for human health. Burn wound victims are particularly susceptible to MRSA infection in the nosocomial environment (Goudarzi et al., 2019). This comes as a result of a reduced immune response from the patient and disruptions to the physical barriers protecting the skin from colonization, resulting in a poor prognosis for burn wound patients infected with MRSA (Goudarzi et al., 2019). For these reasons, outbreaks of MRSA infections in burn units often have catastrophic results.

While S. aureus infections have clear consequences on public health, deleterious effects are also observed in the dairy industry. S. aureus infections, including those of MRSA, are one of the main causative agents of mastitis, both in human and bovine populations (Field et al., 2016). Not only is this a threat to the health of humans and lactating animals but it also affects the quality of milk produced while increasing the burden of costs and care in both cases. Indeed, mastitis represents the most persistent disease in dairy cows and is associated with financial losses of \$19-32 billion per annum (Ryan et al., 2021).

Due to the continued rise in antibiotic resistant strains recovered from infections, combined with the reduced effectiveness of antibiotics, it has become imperative that alternative antimicrobials be developed. Therapeutics with the ability to combat biofilm formation by interfering with quorum sensing processes or by inhibiting absorption offer substitute modes of actions to traditional antimicrobials. The use of dual-antimicrobials with differing modes of action as a means of overcoming bacterial resistance is an attractive idea, taking advantage of the synergistic effects that these antimicrobials have on each other (Field et al., 2016). Such antimicrobials include the lantibiotic class of bacteriocins, bacteriophages and their lysins. The aim of this review is to provide an updated evaluation of the bacteriocins, phages and phage endolysins that show potential to combat MRSA in the nosocomial environment.

\section{GENETICS AND VIRULENCE OF METHICILLIN-RESISTANT S. aureus}

The virulence and antibiotic resistance traits of $S$. aureus are governed by genes present on its circular chromosome

TABLE 1 | Current antibiotic treatment of MRSA and newly developed antibiotics to treat MRSA.

\begin{tabular}{lcl}
\hline Antibiotic & MIC for $\mathbf{S}$. aureus & References \\
\hline Vancomycin & $0.25-1 \mathrm{mg} / \mathrm{L}$ & LaPlante, 2007 \\
Mupirocin & $0.94-1024 \mathrm{mg} / \mathrm{L}$ & LaPlante, 2007 \\
Ceftaroline & $1 \mathrm{mg} / \mathrm{L}$ & Jones et al., 2010 \\
Dalbavancin & $0.06 \mathrm{mg} / \mathrm{L}$ & Smith et al., 2015 \\
Oritavancin & $0.06 \mathrm{mg} / \mathrm{L}$ & Mendes et al., 2014 \\
Nemonoxacin & $<0.3-2 \mathrm{mg} / \mathrm{L}$ & Chen et al., 2009
\end{tabular}




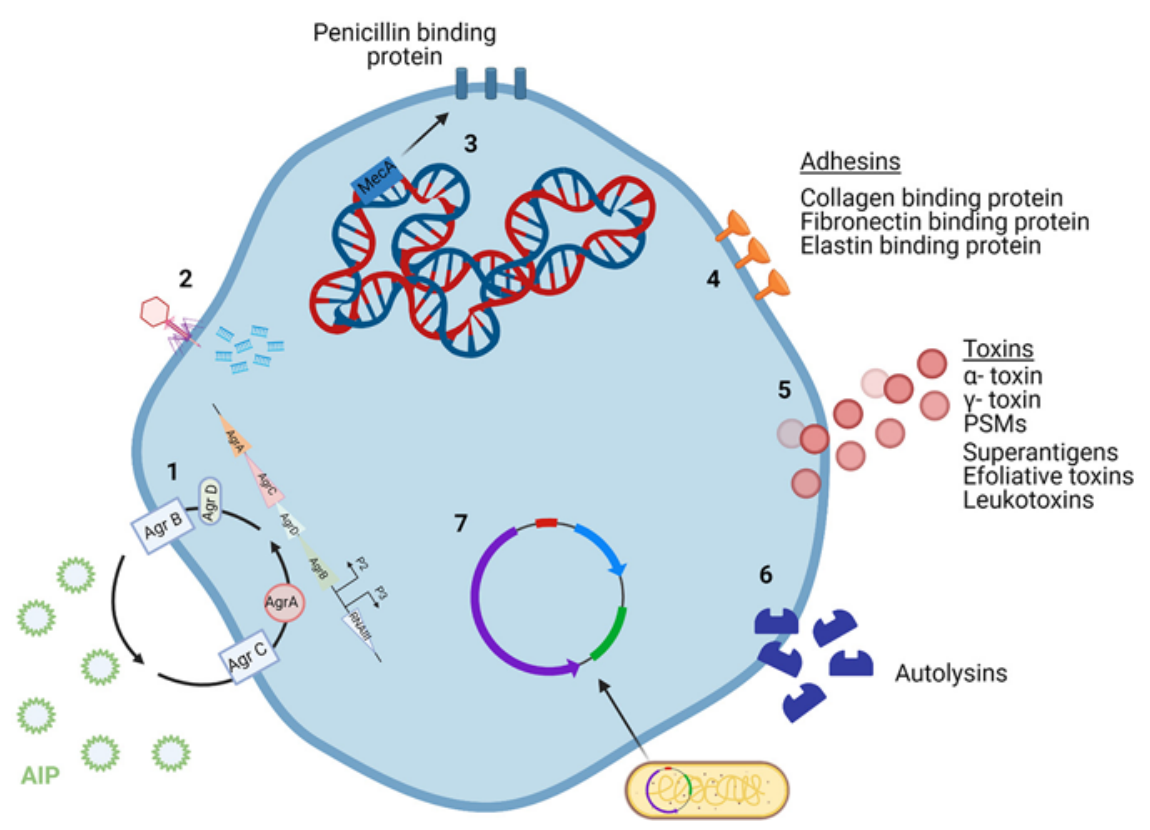

FIGURE 1 | Staphylococcus aureus mechanisms of virulence. (1) The agr quorum sensing system uses AIP levels to regulate cell wall proteins. (2) Phages incorporate their DNA into the bacterial cell genome. (3) The core genome of $S$. aureus contains a variety of virulence genes, including mecA which encodes for methicillin resistance. (4) Adhesins are surface proteins used to bind to host tissue. (5) Toxins secreted by the bacterial cell damage host tissue and can be encoded by the core genome or MGEs. (6) Autolysins break down peptidoglycan in the cell wall and so can attack other cells. (7) Plasmids carry virulence and antibiotic resistance genes that can be incorporated into the genome of bacterial cells. Created using Biorender.com.

and extrachromosomal components. These genes can be easily transferred between different bacteria, be it other staphylococcal strains or other Gram positive bacteria (Lowy, 1998). Despite this propensity for genetic exchange, $S$. aureus comprises a conserved genome, lending to the notion that $S$. aureus is a clonal species (Feil et al., 2003). In terms of diversity amongst this species, mobile genetic elements (MGEs) are present which include a variety of prophages and phage-related genomic islands, including $S$. aureus pathogenicity islands (SaPIs), staphylococcal chromosome cassettes (SCCs), transposons and plasmids (Figure 1; Lindsay, 2010; Lindsay et al., 2012). The prophages supply the bacteria with virulence factors necessary for a pathogenic $S$. aureus strain to effectively infect a mammalian host cell (Brüssow et al., 2004; Lindsay, 2010). MRSA strains carry a $m e c A$ gene that encodes a penicillin-binding protein that confers methicillin resistance (Enright et al., 2002). Methicillin resistance in $S$. aureus strains can also be mediated by the presence of a $\operatorname{mec} C$ gene, however, this is a less likely occurrence (Newstead et al., 2020). This gene is found on the staphylococcal cassette chromosome, mec, which is also a mobile genetic element (Enright et al., 2002). While there are five main SCCmec types (I$\mathrm{V})$, types I-III are largely found to be the cause of nosocomial S. aureus infection (Collins et al., 2010). The evolution of community acquired (CA) MRSA has been considered to be a result of increased virulence in MRSA strains. These strains have incorporated MGEs containing enhanced virulence genes into their genome. This allowed for MRSA strains, which previously had only been found in the nosocomial environment, to occupy a new niche and infect healthy individuals in the community (Otto, 2012).

The genes responsible for $S$. aureus infection fall under three categories: immunomodulators, adhesins, and toxins. Immunomodulators are proteins that prevent the onset of the host immune response (Figure 2). Adhesins are proteins attached to the surface of the cell, allowing for the bacterium to attach to various tissues of the host (Figure 1). Toxins are proteins that are secreted by the cell to cause damage to the host tissue (Figure 1; Collins et al., 2010). Toxins such as $\alpha$-toxin, $\gamma$ - toxin and phenol soluble modulins (PSMs) are encoded by the core genome of most $S$. aureus strains. PSM-mec is an exception in that it is a PSM that is encoded by MGEs. PSMs are amphipathic peptides that have demonstrated cytolytic capabilities toward neutrophils (Otto, 2012). MGEs encode for a variety of other toxins including superantigens, exfoliative toxins and leukotoxins (Chatterjee et al., 1992; Queck et al., 2009). Panton-Valentine leucocidin (PVL) is a pore-forming bi-compartmental toxin. Initially, it was believed that the presence of PVL genes in the genome of MRSA strains led to the increased virulence of those strains. This was because PVL genes $l u k S$ and $l u k F$ were found predominantly in CA-MRSA, with very little evidence for their presence in hospital acquired (HA) MRSA (Vandenesch et al., 2003). However, evidence has since emerged showing that PVL genes have been found in HA-MRSA strains (Otto, 2012). Bacterial autolysins are enzymes produced by the cell to accommodate cell division. Autolysins are encoded by atl and are capable of breaking down peptidoglycan in the cell wall by means 


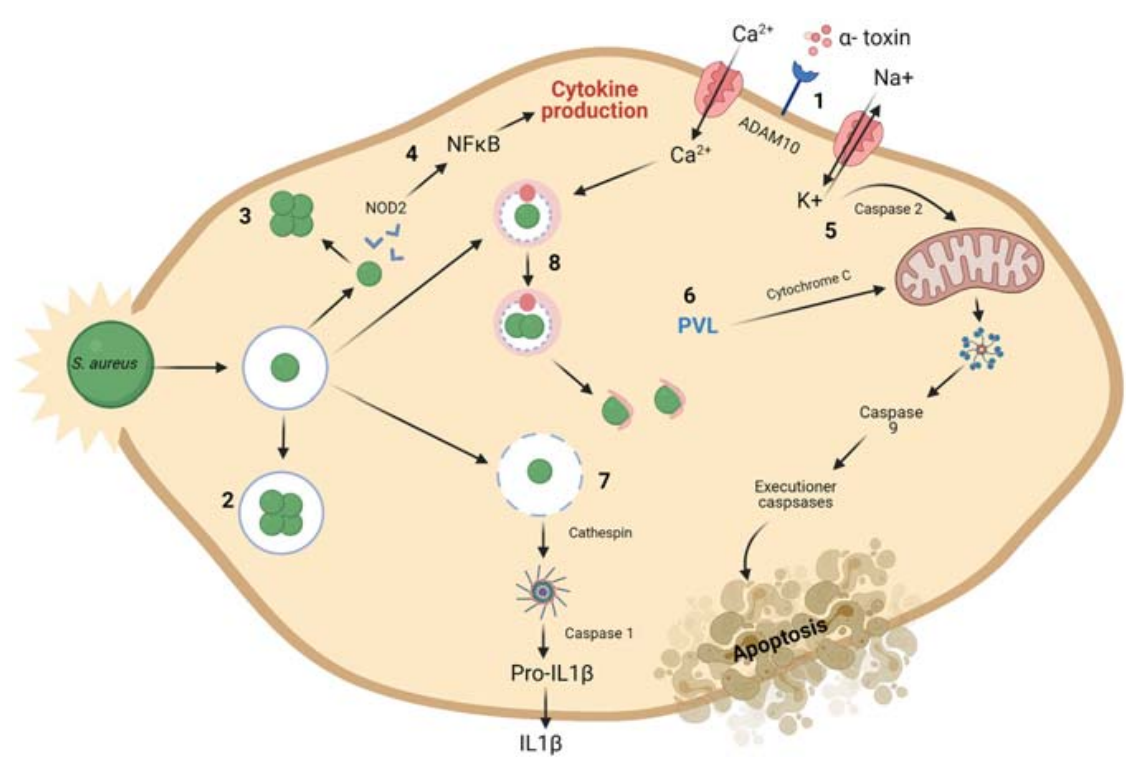

FIGURE 2 | Mechanisms for intracellular preservation of $S$. aureus and induction of cell death. (1) The ADAM10 receptor is a target for formation of $\alpha$-toxin pores on the cell membrane. (2) S. aureus may survive and grow once engulfed in endosomes. (3) or in the cytoplasm of the cell. (4) $S$. aureus present in the cytoplasm are recognized by NOD2 and subsequent activation of NFKB occurs resulting in the production of cytokines. Mitochondrial permeabilization may result in apoptosis. (5) This is brought about by a potassium efflux caused by $\alpha$-toxin build up and subsequent caspase 2 activity. (6) The presence of PVL also cause disruptions to the mitochondrial membrane. This leads to chain of activation involving cytochrome C, caspase 9 and executioner caspases resulting in apoptosis of the cell. (7) Damaged phagosomes release cathepsin, activating the inflammasome and caspase 1. This activation results in cellular secretion of IL $1 \beta$, followed by cell death. A process known as pyronecrosis. (8) Bacteria can replicate within autophagosomes, which have collected cellular contaminants, until they can escape at which point they can induce cell death. Macroautophagy is also said to be activated by $\mathrm{Ca}^{2+}$ (Fraunholz and Sinha, 2012). Created using Biorender.com.

of their glucosaminidase and amidase activities (Haghighat et al., 2017). The physiology of S. aureus is controlled by multiple regulatory systems, including agr (accessory gene regulator) system. The agr system is an important regulator for the virulence capabilities of $S$. aureus. This quorum sensing system operates by monitoring the production of the autoinducing peptide (AIP) and regulating cell wall-associated protein expression accordingly (Traber et al., 2008).

Small-colony variants (SCVs) are bacterial variants that have lower metabolic activity than standard $S$. aureus cells and are also more readily able to resist the action of antibiotics (De Maesschalck et al., 2020). Their ability to resist antibiotics comes from their reduced metabolic rate and slow growing phenotype (Leimer et al., 2016). There is growing support for the relevance of SCVs in a clinical setting as evidence continues to emerge that they are contributing to the development of antibiotic resistance (Peyrusson et al., 2020). From a clinical perspective, there is little known on how induction of SCVs in patients arises (Leimer et al., 2016). The ability of S. aureus to persist inside eukaryotic cells is a driving force behind chronic S. aureus infections (Röhrig et al., 2020). S. aureus intracellular persistence is achieved through various mechanisms, as demonstrated in Figure 2. Bacterial cells replicate either in the cell cytoplasm having escaped the phagosome, or within the phagosome itself. Once intracellular, S. aureus cells have successfully evaded eradication and induced cell death through pyronecrosis and apoptosis (Fraunholz and Sinha, 2012). Staphylococcal toxins, such as PVL, can trigger pyroptosis in keratinocytes, resulting from activation of the inflammasome induced by caspase 1 (Soong et al., 2015).

Staphylococcus aureus is commonly recognized as one of the most significant clinical pathogens in terms of biofilm formation capacity on implanted medical devices (Kelly et al., 2012). The ability of a bacterial species to form biofilms significantly increases its likelihood of withstanding antimicrobial attack. In contrast to planktonic cells, the bacterial cells present in a biofilm are physiologically and physically protected from antibiotics by sequential layers of growing microbes (de la Fuente-Núñez et al., 2013). While the exterior layers of the biofilm may be killed on exposure, the interior layers remain untouched and so can re-establish the bacterial population which then reforms the biofilm once the antimicrobial effects have subsided. The ability of $S$. aureus to form biofilms and colonize efficiently is aided by surface proteins including SasX (Figueiredo et al., 2017).

\section{BACTERIOCINS}

\section{Background}

Bacteria can produce antimicrobial peptides, known as bacteriocins, which provide defense against other closely related strains (narrow spectrum) or unrelated species (broad spectrum). Bacteriocins were first discovered in Gratia (1925) and have been the focus of much research due to their bactericidal nature and ability to inhibit the growth of pathogenic bacteria. It is thought that the majority of archaea and bacteria produce 
one if not more bacteriocins (Klaenhammer, 1988). Although the process of producing bacteriocins has been shown to be quite energy demanding on the cell, the staggering amount of bacteria that produce bacteriocins supports the idea that this activity is central to the competitiveness of bacteria in some way, be it through killing and/or communication (Gillor et al., 2009). While early applications for bacteriocins were primarily based on food preservation, recent repurposing of these peptides has led to the development of therapeutics for human health. As shown in Figure 3, bacteriocins act as signaling peptides to communicate with surrounding communities of microbes, as well as facilitating communication with mammalian immune cells; colonizing peptides allowing for the growth of their producing bacteria and enabling cells to occupy a niche in a competitive environment (Riley and Wertz, 2002); or killing peptides which act to remove competing bacteria from the environment.

Bacteriocins can be divided into two classes: Class I, lanthioine-containing bacteriocins (also referred to as lantibiotics), and Class II, non-lanthionine-containing bacteriocins (Cotter et al., 2005; Figure 4). In Class I lantibiotics, post-translational modifications result in the formation of the unique amino acids, b-methyllanthionine and lanthionine. There has been rapid growth in the identification of new lantibiotics so it comes as no surprise that they are gaining traction in the search for new antimicrobials. Some lantibiotics, such as lacticin 3147 , are composed of two peptides, while nisin is composed of a single peptide. A key component in the biosynthesis of peptidoglycan is lipid II, which many lantibiotics such as nisin have the ability to bind. This binding process is generally followed by the formation of a pore in the target bacterial cell (Piper et al., 2009). The N- terminus present in the hinge region of the peptide is critical to this binding process (Healy et al., 2013). The $\mathrm{N}$ - terminus is composed of three (b-methyl) lanthionine rings, termed rings $\mathrm{A}, \mathrm{B}$, and $\mathrm{C}$ (incorporated at post-translational level). The $\mathrm{N}$ - and $\mathrm{C}$ - termini are linked by a hinge region (Field et al., 2008). The C- terminus contains two rings of its own, termed rings $\mathrm{D}$ and $\mathrm{E}$. The $\mathrm{C}$ terminus is responsible for the antimicrobial activity which allows for pore

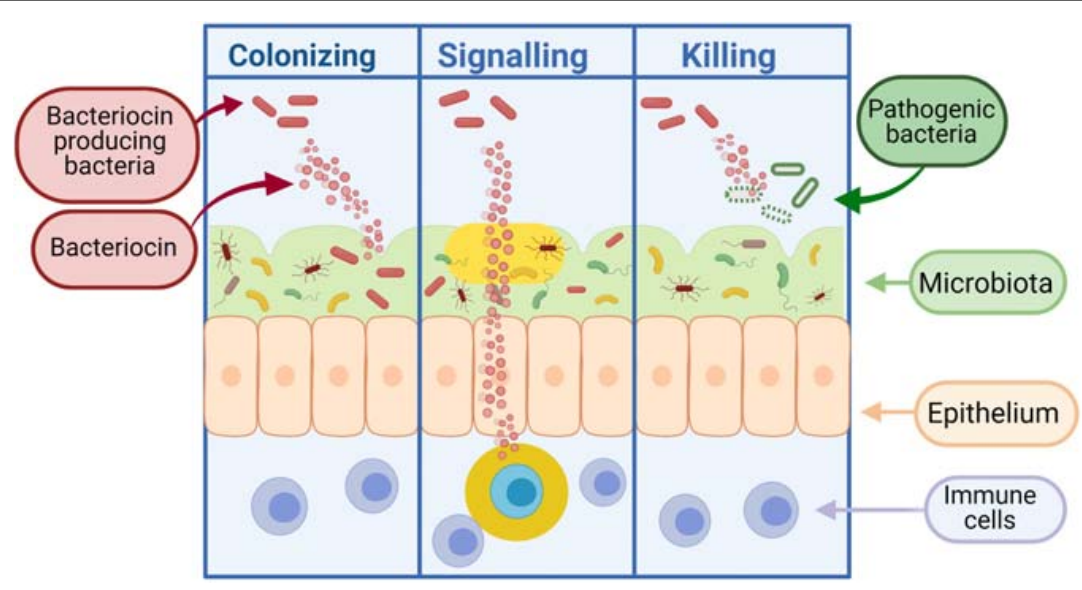

FIGURE 3 | Bacteriocins can function as colonizing peptides (by opening up a niche in the environment for their producing bacteria to occupy), as signaling peptides [to communicate with the immune system or other surrounding bacteria, or as killing peptides (to eradicate bacteria threatening the survival of their producing bacteria)] (Dobson et al., 2012). Created using Biorender.com.

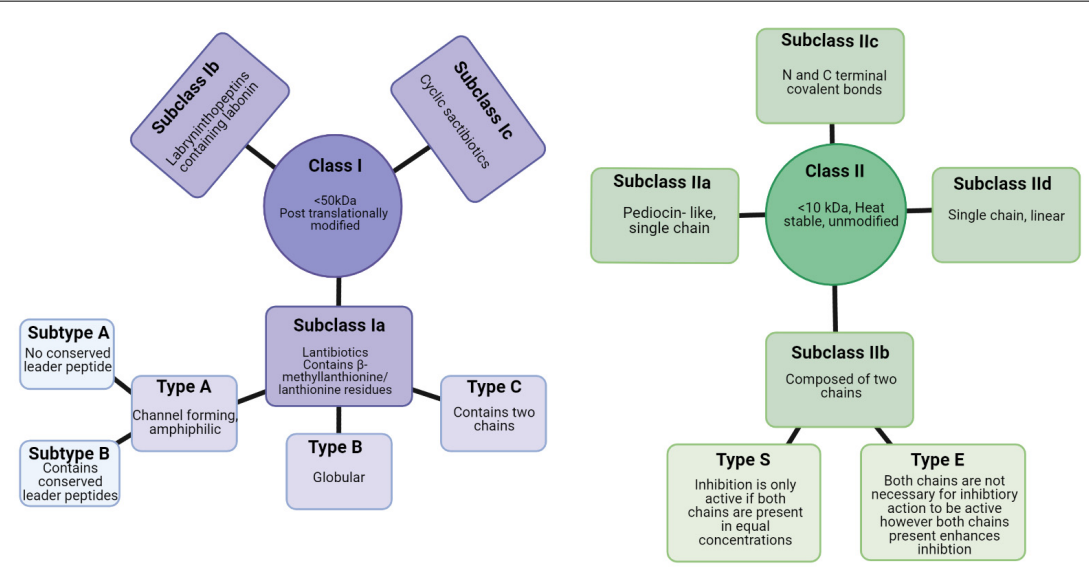

FIGURE 4 | Class I and class || bacteriocins produced from Gram positive bacteria (Newstead et al., 2020). Created using Biorender.com. 
formation in the bacterial cell (Healy et al., 2013). This results in the flow of ions and cytoplasmic components out of the target cell leading to extreme damage and subsequent cell death (Field et al., 2008). The bacteriocin producer is generally resistant to its own bacteriocin due to the presence of immunity gene(s) within the bacteriocin gene cluster in addition to the production of immunity protein(s).

As a potential basis for new antimicrobial therapies, bacteriocins have several advantages over conventional antibiotic treatments. Bacteriocins generally have narrow to broad inhibition spectra - which means that insensitive commensal bacteria in microbiomes remain unperturbed. In the gut, for example, disruptions to the surrounding microbiota as a consequence of broad-spectrum antibiotic treatment can lead to further complications and enable pathogenic bacteria to flourish. A specific example of this is Clostridioides difficile infections which can flourish in the gut following eradication of commensals via antibiotic use and can cause mild to fatal diarrhea (Buffie et al., 2012). The mode of action for bacteriocins is generally different from that of specific antibiotics, allowing bacteriocins to kill bacterial strains which are resistant to antibiotics (Cotter et al., 2013). Furthermore, the concentrations at which bacteriocins exhibit antimicrobial activity are far less than those required by antibiotics (Newstead et al., 2020). Finally, bacteriocins lend themselves to the production of derivatives through peptide bioengineering (Cotter et al., 2013; Field et al., 2015). In this way, variants with enhanced and desirable characteristics can be produced, yielding bacteriocins that are more "fit for purpose" in terms of therapeutic applications. For example, Field et al. (2008) has generated variants of nisin, N20P, K22S and M21V which exhibit increased antimicrobial activity to a variety of pathogens including various staphylococci.

\section{Bacteriocins Utilizing Nanotechnology}

Delivery systems have been developed to minimize degradation of bacteriocins by gastric enzymes and maximize therapeutic effect. The use of nanotechnology to enhance characteristics such as antimicrobial activity, bioavailability, short half-life and delivery potential of bacteriocins is a relatively new area of research. Nanotechnology is the use of 1-100 nm-sized particles known as nanoparticles that are made of carbon, metal or organic matter (Sulthana and Archer, 2020). Research on lipid-based nanoparticles has led to the development of nanoliposomes and solid lipid nanoparticles (SLN) (Banerjee, 2001; da Silva Malheiros et al., 2012). Phytogylogen nanoparticles and chitosan/alginate nanoparticles fall under the category of carbohydrate-based nanoparticles (Fahim et al., 2016). Many studies have shown how nanoparticles can improve the capabilities of bacteriocins. A chitosan/alginate combination was used to encapsulate nisin and resulted in increased activity against the S. aureus ATCC 19117 strain in ultra-filtered feta cheese (Zohri et al., 2013). An injectable polysaccharide gel has been shown to effectively encapsulate and release nisin to treat $S$. aureus infections and maintain antimicrobial activity for up to 10 days (Flynn et al., 2020). The composition of the gel included oxidized dextran, glycol chitosan and alginate which was activated by the addition of hydrazine groups.
Researchers varied the incorporation of gel components which allowed for manipulation of the swelling capabilities of the gel and the subsequent release of nisin. Conjugation with nanosized gold or silver particles increases binding to the negatively charged bacterial membrane due to the positive charge on the nanoparticles. Oxidative stress is then induced in the bacterial cell and subsequent cell death occurs (Seil and Webster, 2012). Incorporation of bacteriocins into polymeric nanofibers is achieved by electrospinning the bacteriocin (Fahim et al., 2016). In particular, this technique has enhanced bacteriocins to treat $S$. aureus and MRSA infection in vitro and in vivo. Heunis et al. (2013) developed a nisin nanofiber wound dressing which reduced the bacterial load of skin wounds on mice by five logs after 7 days of treatment when compared with the control (Heunis et al., 2013). Another study examining the effect of nisin-incorporated nanofibers on a biofilm-forming MRSA strain found that the treatment reduced biofilm formation by 88\% (Ahire and Dicks, 2015) Although the use of nanotechnology to develop bacteriocin treatment is showing potential, much is still unknown, including if and what potential interactions take place between the nanomaterials, peptides and target bacteria. More studies are required to determine the impact this technology has on the antimicrobial activity of the bacteriocin. For clinical studies, toxicity risks and pharmacokinetics data need to be established.

\section{Limitations of Bacteriocins}

Although treatments utilizing bacteriocins have various advantages over antibiotics, this form of therapy also has numerous shortcomings. While in some respects the narrow activity spectrum of most bacteriocins has its benefits, as previously mentioned, this can also be seen as a negative. Indeed, it is essential that the infection-causing microbe(s) are known for treatment to be successful, rendering administration of the treatment slightly more time consuming than that of antibiotic therapy as the causative agent(s) is identified. When considering the use of orally administered therapeutics, it is important to consider factors such as bioavailability, half-life and absorption achieved by the intestine. An issue contributing to the challenge of using bacteriocins as therapeutics is their inability to survive the conditions of the gastrointestinal tract. This is a result of peptide degradation by digestive enzymes and changes in $\mathrm{pH}$, and has been demonstrated in various in vitro and in vivo studies (Heinemann and Williams, 1966; Jarvis and Mahoney, 1969; Newstead et al., 2020). The sensitivity of most bacteriocins to gut proteases dramatically decreases their half-life in comparison to antibiotics (Hols et al., 2019). One study examined the ability of the two-component, anti-C. difficile bacteriocin, thuricin $\mathrm{CD}$, to survive gastric enzymes and the subsequent bioavailability of the bacteriocin. The $\operatorname{Trn} \beta$ peptide of the bacteriocin was degraded by $\alpha$ - chymotrypsin and pepsin (Rea et al., 2014). Some studies have shown that these issues can be overcome through peptide bioengineering. Specifically, researchers showed that proteolytic cleavage of a chemically synthesized peptide was reduced following the addition of d-amino acids (Hoskin and Ramamoorthy, 2008). Parenteral administration of bacteriocins will circumvent exposure of peptides to gut proteases, however, 
some protease interaction still takes place due to fibrinolysis and hemostasis occurring in the bloodstream (Mathur et al., 2017). Furthermore, some bacteriocins have exhibited immunogenic activity which could compromise their use for systemic infections (Soltani et al., 2021). While bacteriocins are generally considered non-toxic, studies have shown that at high concentrations bacteriocins show signs of cytotoxicity toward various cell lines (Chalekson et al., 2003; Soltani et al., 2021). A limited number of studies have examined the toxicity of bacteriocins in vivo (Soltani et al., 2021). One study investigated the immunogenicity and toxicity of the peptide P34 on BALB/c mice (de Almeida Vaucher et al., 2011). There was no apparent increase in antibody titer or hypersensitivity reaction in the treated group. However, histological changes in the spleen were observed in the group administered P34 (de Almeida Vaucher et al., 2011).

The methods by which purified bacteriocins are produced are less than satisfactory due to slow processes and high costs. Traditionally, purified bacteriocin is produced by batch fermentation with the producer strain. This strategy requires specific components depending on which bacteriocin is being produced, creating difficulties in mass producing a variety of bacteriocins (Hols et al., 2019).

Bacterial exposure to even low concentrations of bacteriocin may result in resistance (Van Schaik et al., 1999). This cellular response is a means of adapting to and surviving the changing conditions in the environment. Resistance is achieved via alterations to structural components such as the cell wall and membrane of the bacterial cell. These alterations can affect cellular regulation with regard to membrane lipid composition, electrical fluidity and cell wall density (Mantovani and Russell, 2001). Lantibiotics interact with lipid II contained in the cytoplasmic membrane and subsequently create a pore. In addition to that, some lantibiotics, such as nisin, prevent the process of binding with lipid II, which in turn stops the synthesis of the cell wall. In contrast to that, the interaction of two-component lantibiotics with the cytoplasmic membrane is mediated by the A1 peptide. Once this interaction has been established, lipid II is then targeted (Wiedemann et al., 2006). Class II bacteriocins use the mannose-phosphotransferase system to interact with the cell membrane and cause subsequent permeability of the membrane (Nissen-Meyer et al., 2009). L. monocytogenes has demonstrated resistance to bacteriocins pediocin PA-1, nisin and leuconocin S (Bruno and Montville, 1993) Another example of bacterial resistance was observed in Bacillus cereus and Paenibacillus polymyxa which produce the degradation enzyme, nisinase, capable of degrading nisin (Meade et al., 2020). Only limited knowledge exists on S. aureus resistance to bacteriocins. Due to the restricted number of in vivo studies examining bacteriocin resistance, the majority of knowledge in this area is derived from in vitro studies. While this information gives an insight into how bacteriocin resistance may occur in a clinical setting, further studies are necessary to fully understand the threat of bacterial resistance in such a setting. However, nanotechnology and combinatorial therapies should help to overcome bacterial resistance to bacteriocins.

\section{In vitro and in vivo Experiments of Bacteriocins Against MRSA}

Staphylococcus capitis APC2923 isolated from the epithelial surface layer of the toe web space is known to produce a bacteriocin termed nisin J (O'Sullivan et al., 2019). This bacteriocin is a nisin variant that has shown activity against clinically significant gram-positive pathogens such as MRSA. Nisin J exhibited increased antimicrobial activity on 12 out of 13 strains tested when compared to nisin $\mathrm{A}$ and nisin $\mathrm{Z}$ in vitro. Gallidermin is a peptide produced by Staphylococcus gallinarum that has lytic activity against both methicillin sensitive $S$. aureus and MRSA strains (Manosroi et al., 2010; Bengtsson et al., 2018). The cytotoxic and pro-inflammatory effects of gallidermin on fibroblasts were examined in vitro. Only high levels of gallidermin invoked a minor response from CXCL8 and interleukin-6. The bacteriocin was able to suppress an inflammatory response caused by the S. aureus infection (Bengtsson et al., 2018). While gallidermin is capable of suppressing the growth of $S$. aureus biofilms, the ability of the bacteriocin to eradicate a biofilm that has already formed is less impressive (Saising et al., 2012). Similarly, hyicin 4244 has shown an ability to inhibit MRSA strains and reduce an $S$. aureus biofilm. This bacteriocin is produced by Staphylococcus hyicus 4244 and classed as a sactibiotic (de Souza Duarte et al., 2018). Hyicin was examined, in vitro, for its ability to inhibit mastitis-causing $S$. aureus isolates. All isolates tested were sensitive to hyicin activity. Furthermore, hyicin showed impressive ability at biofilm eradication, reducing the number of viable cells by $99.9 \%$. BacSp222 has also demonstrated an ability to inhibit various S. aureus strains, including MRSA. This bacteriocin, produced by Staphylococcus pseudintermedius, is a class II staphylococcin. BacSp222 was active against 15 strains in vitro, however, it exhibited cytotoxic effects toward eukaryotic cells (Wladyka et al., 2015). Jang et al. (2020) have isolated a cytoplasm-bound thermolabile bacteriocin from $S$. epidermidis which appears to be highly active against $S$. aureus and MRSA strains in vitro. Liu et al. (2011) developed a probiotic capable of producing lysostaphin with the aim of reducing toxic shock syndrome toxin (TSST)-producing $S$. aureus. Elevated $\mathrm{pH}$, carbon dioxide, oxygen and protein levels in the vaginal tract creates an ideal environment for $S$. aureus growth and subsequent production of TSST (Beller and Schweppe, 1979; McCormick et al., 2001). A plasmid containing genes for lysostaphin expression, a promoter responsible for response under neutral $\mathrm{pH}$ conditions and a signal sequence was transformed into the probiotic strain Lactobacillus plantarum WCFS1. This lysin-modified probiotic produced zones of clearing against an $S$. aureus strain, which produces TSST, at a neutral $\mathrm{pH}$ in vitro (Liu et al., 2011).

Studies have been carried out utilizing dual antimicrobial actions (bacteriocins and antibiotics combined) for treating $S$. aureus infections. Lactococcus garvieae produces a bacteriocin, termed garvicin KS, which is composed of three peptides. Garvicin KS has a broad spectrum of inhibition against Gram positive bacteria as well as some Gram negative bacteria from the genus Acinetobacter (Chi, 2018). When tested against a variety of $S$. aureus strains, garvicin KS was active against all 
strains but three. Using a checkerboard assay garvicin KS was shown to successfully inhibit $S$. aureus growth in conjunction with nisin and farnesol. This synergistic combination reduced the minimum inhibitory concentration (MIC) of garvicin KS by a factor of 8 (Chi and Holo, 2018). Enterocins DD28 and DD93, Class IIb bacteriocins produced by E. faecalis 28 and E. faecalis 93, respectively, have also demonstrated activity against various $S$. aureus strains, including MRSA. They have exhibited a synergistic effect when used in combination with antibiotics such as kanamycin and erythromycin, resulting in increased activity against MRSA strains. Enterocins DD28 and DD93 are capable of effectively preventing MRSA biofilm growth as well as blocking initial biofilm establishment. This was demonstrated by a 100-fold reduction of MRSA-S1 biofilm cell numbers following treatment with Enterocins DD28 and DD93 in combination with kanamycin and erythromycin (Al Atya et al., 2016). Ellis et al. (2019) utilized sub-inhibitory concentrations of lacticin3147 to promote the dual effect of penicillin and vancomycin, resulting in the inhibition of various bacterial strains including MRSA. Similarly, this study examined the effects of nisin in combination with methicillin, which also produced impressive anti-MRSA activity (Ellis et al., 2019).

Various in vivo experiments have been performed to determine the effects of bacteriocins against numerous MRSA associated infections, as well as the effects on the host. Sublancin is a bacteriocin produced by Bacillus subtilis 168 and was examined for its anti-MRSA activity in a mouse model. The mice were intraperitoneally infected with MRSA ATCC43300. Sublancin was shown to reduce the bacterial load of the intraperitoneal cavity of the mice. On day 3 of the study, $65 \%$ of the control group had died, while an increase in the concentration of sublancin administered correlated to an increase in the survival rate of the mice (Wang et al., 2017). Furthermore, the bacteriocin was able to reduce gut inflammation and equilibrate the immune response of the mice by supressing NFKB activation. Another study examined the effect of a combination therapy, involving garvicin $\mathrm{KS}$, penicillin $\mathrm{G}$ and micrococcin $\mathrm{P} 1$, on skin infections on a murine model. The strain used in this study was MRSA Xen31, which is a luciferase-tagged strain allowing for observation of fluorescence to represent live cells. The antimicrobial combination treatment was applied in a hydroxypropyl cellulose-based solution. Following infection with MRSA Xen31, the bacteriocin/antibiotic combination was able to eradicate the infection from the wound, while also outperforming a commonly used antibiotic treatment for skin infection, Fucidin cream (Ovchinnikov et al., 2020).

\section{Clinical Uses of Bacteriocins Against MRSA}

Bacteriocins are being used successfully in the food industry to control and inhibit bacterial growth, indeed, nisin was first introduced as a food preservative (E324) in 1969. In veterinary medicine, bacteriocins have been proven to be as effective as leading antibiotics for treating and preventing bovine mastitis (Cao et al., 2007; Wu et al., 2007; Klostermann et al., 2010; Kitching et al., 2019). Although nisin had previously been examined for its activity against Mycobacterium tuberculosis (Bavin et al., 1952), its application to combat infections in humans is largely unexplored. In general, studies and clinical trials investigating the efficacy of bacteriocins in humans are limited, with very few addressing $S$. aureus infection. One study that did investigate the ability of nisin to treat human mastitis, which is commonly caused by $S$. aureus, was performed by Fernández et al. (2008). The study was carried out on eight women divided evenly into a treatment and a control group. A nisin solution was applied to the nipple and mammary areola of women in the treatment group, with the control group receiving a placebo solution. Following two weeks of the study, the women in the treatment group had on average 2logs less of a bacterial load compared to the control group. There were no clinical signs of mastitis in the treatment group following two weeks of treatment with nisin; however, mastitis in the control group remained for the entirety of the study. Nisin is currently being investigated in a clinical trial examining its effectiveness at treating infections causing ventilator-associated pneumonia, and one of the pathogens of interest in this trial is $S$. aureus (Gradisteanu Pircalabioru et al., 2021). Intrabiotics is currently performing a phase I clinical trial utilizing nisin and the protegrin-like peptide IB-367 to treat acne (Gradisteanu Pircalabioru et al., 2021).

Many bacteriocins produce impressive activity against S. aureus, most notably MRSA strains (Table 2). However, there is a lack of knowledge surrounding the full extent of the toxic effects that these peptides impart on human hosts. Yet due to the nature of MRSA infections and the degree to which such infections remain a problem in the nosocomial environment, further research into bacteriocin toxicity versus their anti-MRSA efficacy is warranted (Newstead et al., 2020).

\section{PHAGES}

\section{Background}

Phages are viruses that infect bacteria and may enter either the lytic or lysogenic life cycle following infection. During the lytic lifecycle, infecting phages undergo phage replication and assembly followed by release from the infected cell subsequently resulting in cell death. More specifically, following the assembly and packaging of phage particles in the infected cell, enzymes known as endolysins are produced by the phage to lyse the bacterial host from within. During the lysogenic lifecycle, the phage genome integrates into the bacterial host genome or may be present in the cell in the form of a plasmid. The phage genome then replicates with the host genome and is referred to as a prophage (Salmond and Fineran, 2015). The lysogenic phage/prophage essentially remains dormant until the host cell is exposed to a stressor such as nutrient limitation, in which case the prophage is induced to lyse the host cell. Phages can be solely lytic, generally referred to as lytic phages, or can have the capacity to enter lysogeny, referred to as lysogenic phages.

Phages may have single-stranded or double-stranded RNA or DNA genomes housed in the capsid head of the phage. The Caudovirales order of phages have double-stranded linear 
TABLE 2 | List of Bacteriocins active against S. aureus.

\begin{tabular}{|c|c|c|c|c|c|c|}
\hline Bacteriocin & Producing strain & Class & S. aureus target strains & $\begin{array}{l}\text { Inhibitory } \\
\text { potential (MIC) }\end{array}$ & Pros and cons & References \\
\hline Hominicin & $\begin{array}{l}\text { Staphylococcus hominis MBBL } \\
2-9\end{array}$ & la $\mathrm{A} 1$ & $\begin{array}{l}\text { S. aureus ATCC } 25923 \\
\text { S. aureus (MRSA) ATCC } \\
11435 \\
\text { S. aureus (VISA) CCARM } \\
3501\end{array}$ & $\begin{array}{l}0.06 \mu \mathrm{g} / \mathrm{mL} \\
0.96 \mu \mathrm{g} / \mathrm{mL} \\
3.82 \mu \mathrm{g} / \mathrm{mL}\end{array}$ & & Sung et al., 2010 \\
\hline Nisin J & $\begin{array}{l}\text { Staphylococcus capitis APC } \\
2923\end{array}$ & la A1 & $\begin{array}{l}\text { S. aureus DPC } 7016 \\
\text { MRSA DPC } 5645\end{array}$ & ${ }^{*} \mathrm{ND}$ & & O'Sullivan et al., 2019 \\
\hline Pumilicin 4 & Bacillus pumilus & & $\begin{array}{l}\text { MRSA } 1297 \\
\text { MRSA } 1302 \\
\text { MRSA } 1304\end{array}$ & ${ }^{*} \mathrm{ND}$ & Pro: Active against VRE strains & Aunpad and Na-Bangchang, 2007 \\
\hline Epidermin & Staphylococcus epidermidis & la $\mathrm{A} 1$ & $\begin{array}{l}\text { S. aureus SG } 511 \\
\text { S. aureus E88 }\end{array}$ & $\begin{array}{l}8 \mu \mathrm{g} / \mathrm{mL} \\
8 \mu \mathrm{g} / \mathrm{mL}\end{array}$ & & $\begin{array}{l}\text { Kellner et al., 1988; Schnell et al., } \\
\text { 1988; Bonelli et al., } 2006\end{array}$ \\
\hline Pep5 & Staphylococcus epidermidis & la $\mathrm{A} 1$ & $\begin{array}{l}\text { S. aureus FPR3757 (MRSA) } \\
\text { S. aureus USA300 (MRSA) } \\
\text { S. aureus MW2 (MRSA) } \\
\text { S. aureus MSSA252 } \\
\text { S. aureus Newman }\end{array}$ & $\begin{array}{l}13.15 \mu \mathrm{g} / \mathrm{mL} \\
13.15 \mu \mathrm{g} / \mathrm{mL} \\
23 \mu \mathrm{g} / \mathrm{mL} \\
9.86 \mu \mathrm{g} / \mathrm{mL} \\
13.15 \mu \mathrm{g} / \mathrm{mL}\end{array}$ & & Oppedijk, 2017 \\
\hline Gallidermin & Staphylococcus gallinarum & la A1 & $\begin{array}{l}\text { S. aureus SG } 511 \\
\text { S. aureus E88 } \\
\text { MRSA }\end{array}$ & $\begin{array}{l}4 \mu \mathrm{g} / \mathrm{mL} \\
8 \mu \mathrm{g} / \mathrm{mL}\end{array}$ & $\begin{array}{l}\text { Pro: Anti-staphylococcal biofilm } \\
\text { activity }\end{array}$ & $\begin{array}{l}\text { Kellner et al., 1988; Kempf et al., } \\
\text { 2001; Bonelli et al., 2006; Götz } \\
\text { et al., } 2014\end{array}$ \\
\hline Hyicin 4244 & Staphylococcus hyicus 4244 & Ic & S. aureus 4124 & ${ }^{*} \mathrm{ND}$ & $\begin{array}{l}\text { Pro:Anti-staphylococcal biofilm } \\
\text { activity } \\
\text { Pro: Active against CoNS }\end{array}$ & de Souza Duarte et al., 2018 \\
\hline BacSp222 & $\begin{array}{l}\text { Staphylococcus } \\
\text { pseudintermedius } 222\end{array}$ & Ild & $\begin{array}{l}\text { MRSA USA300 strain } \\
\text { FPR3757 } \\
\text { S. aureus KB/8658 } \\
\text { S. aureus ATCC } 25923 \\
\text { S. aureus DSM } 26258 \\
\text { (CH91) }\end{array}$ & $\begin{array}{l}5 \mu \mathrm{g} / \mathrm{mL} \\
7.7 \mu \mathrm{g} / \mathrm{mL} \\
5.9 \mu \mathrm{g} / \mathrm{mL} \\
5.44 \mu \mathrm{g} / \mathrm{mL}\end{array}$ & $\begin{array}{l}\text { Con: Significant cytotoxic } \\
\text { activities toward eukaryotic } \\
\text { cells }\end{array}$ & $\begin{array}{l}\text { Wladyka et al., 2015; Pieta et al., } \\
2016\end{array}$ \\
\hline Garvicin KS & Lactococcus garvieae KS1546 & Ile & S. aureus LMGT 3242 & ${ }^{*} \mathrm{ND}$ & $\begin{array}{l}\text { Pro: Broad spectrum of } \\
\text { inhibition }\end{array}$ & Chi and Holo, 2018 \\
\hline Epidermicin NI01 & $\begin{array}{l}\text { Staphylococcus epidermidis } \\
224\end{array}$ & Ild & $\begin{array}{l}\text { MRSA s37 } \\
\text { MRSA s41 } \\
\text { MRSA s71 } \\
\text { S. aureus } 1195\end{array}$ & $\begin{array}{l}1-2 \mu \mathrm{g} / \mathrm{mL} \\
1-2 \mu \mathrm{g} / \mathrm{mL} \\
2 \mu \mathrm{g} / \mathrm{mL} \\
2 \mu \mathrm{g} / \mathrm{mL}\end{array}$ & $\begin{array}{l}\text { Pro: Anti-staphylococcal biofilm } \\
\text { activity }\end{array}$ & Sandiford and Upton, 2012 \\
\hline Bactofencin A & $\begin{array}{l}\text { Lactobacillus salivarius } \\
\text { DPC6502 }\end{array}$ & Ild & S. aureus 5246 & $2.7-13.9 \mu \mathrm{g} / \mathrm{mL}$ & & O'Shea et al., 2013 \\
\hline Lysostaphin & Staphylococcus simulans & Illa & MRSA 301 & $0.0625 \mu \mathrm{g} / \mathrm{mL}$ & $\begin{array}{l}\text { Pro: In vitro and in vivo } \\
\text { experiments }\end{array}$ & $\begin{array}{l}\text { Schindler and Schuhardt, 1965; } \\
\text { Dajcs et al., } 2000\end{array}$ \\
\hline
\end{tabular}


TABLE 2 | Continued

\begin{tabular}{|c|c|c|c|c|c|c|}
\hline Bacteriocin & Producing strain & Class & S. aureus target strains & $\begin{array}{l}\text { Inhibitory } \\
\text { potential (MIC) }\end{array}$ & Pros and cons & References \\
\hline Epilancin 15X & $\begin{array}{l}\text { Staphylococcus epidermidis } \\
15 \times 154\end{array}$ & la A1 & $\begin{array}{l}\text { Multi drug resistant } \\
\text { S. aureus }\end{array}$ & ${ }^{*} \mathrm{ND}$ & & $\begin{array}{l}\text { Ekkelenkamp et al., 2005; } \\
\text { Velásquez et al., } 2011\end{array}$ \\
\hline Hyicin3682 & Staphylococcus hyicus 3682 & la A1 & $\begin{array}{l}\text { S. aureus } 2 \mathrm{~S} 2 \\
\text { S. aureus } 4 \mathrm{~S} 1\end{array}$ & ${ }^{*} \mathrm{ND}$ & & Fagundes et al., 2011 \\
\hline C55 & Staphylococcus aureus C55 & $\mathrm{lllb} S$ & MRSA & & $\begin{array}{l}\text { Pro: Active against mupirocin } \\
\text { resistant S. aureus strains }\end{array}$ & Navaratna et al., 1998 \\
\hline Aureocin A53 & Staphylococcus aureus A53 & $\| d$ & S. aureus ATCC 29213 & $769.6 \mu \mathrm{g} / \mathrm{mL}$ & & $\begin{array}{l}\text { Netz et al., 2002; Acedo et al., } \\
2016\end{array}$ \\
\hline Endopeptidase ALE-1 & Staphylococcus capitis EPk1 & Illa & S. aureus FDA209P & $54.2 \mu \mathrm{g} / \mathrm{mL}$ & & Sugai et al., 1997 \\
\hline Nisin M21V & Lactococcus lactis NZ9800 & la $A 1$ & $\begin{array}{l}\text { S. aureus ST } 528 \text { (MRSA) } \\
\text { S. aureus ST } 530 \text { (MRSA) } \\
\text { S. aureus ST } 534 \text { (MRSA) }\end{array}$ & $\begin{array}{l}0.26 \mu \mathrm{g} / \mathrm{mL} \\
0.26 \mu \mathrm{g} / \mathrm{mL} \\
0.52 \mu \mathrm{g} / \mathrm{mL}\end{array}$ & $\begin{array}{l}\text { Pro: Anti-staphylococcal biofilm } \\
\text { activity }\end{array}$ & Field et al., 2008, 2010, 2016 \\
\hline Nisin A & Lactococcus lactis NZ9800 & la A1 & S. aureus MR23 (MRSA) & $8.4 \mu \mathrm{g} / \mathrm{mL}$ & $\begin{array}{l}\text { Pro: Anti-staphylococcal biofilm } \\
\text { activity }\end{array}$ & $\begin{array}{l}\text { Field et al., 2008; Okuda et al., } \\
2013\end{array}$ \\
\hline Sublancin & Bacillus subtilis 168 & la & $\begin{array}{l}\text { S. aureus } \\
\text { MRSA ATCC } 43300\end{array}$ & $\begin{array}{l}>100 \mu \mathrm{g} / \mathrm{mL} \\
15 \mu \mathrm{M}\end{array}$ & & Paik et al., 1998; Wang et al., 2017 \\
\hline Lacticin $Q$ & Lactococcus lactis QU 5 & Ild & S. aureus MR23 (MRSA) & $29.6 \mu \mathrm{g} / \mathrm{mL}$ & $\begin{array}{l}\text { Pro: Anti-staphylococcal biofilm } \\
\text { activity }\end{array}$ & Okuda et al., 2013 \\
\hline BAC-IB17 & Bacillus subtilis KIBGE-IB17 & ${ }^{*} \mathrm{ND}$ & MRSA & $50 \mu \mathrm{g} / \mathrm{mL}$ & & Ansari et al., 2018 \\
\hline Mersacidin & $\begin{array}{l}\text { Bacillus sp. strain HIL } \\
\text { Y-85,54728 }\end{array}$ & Ila & S. aureus 99308 (MRSA) & $1 \mu \mathrm{g} / \mathrm{mL}$ & $\begin{array}{l}\text { Pro: In vitro and in vivo } \\
\text { experiments }\end{array}$ & Kruszewska et al., 2004 \\
\hline Enterocin DD28 & Enterococcus faecalis 28 & Illb & $\begin{array}{l}\text { MRSA ATCC } 43300 \\
\text { MRSA-S1 } \\
\text { MRSA-2 } \\
\text { S. aureus ATCC33862 }\end{array}$ & $\begin{array}{l}200 \mu \mathrm{g} / \mathrm{mL} \\
200 \mu \mathrm{g} / \mathrm{mL} \\
200 \mu \mathrm{g} / \mathrm{mL} \\
100 \mu \mathrm{g} / \mathrm{mL}\end{array}$ & $\begin{array}{l}\text { Pro: Anti- staphylococcal } \\
\text { biofilm activity }\end{array}$ & Al Atya et al., 2016 \\
\hline Enterocin DD93 & Enterococcus faecalis 93 & Illb & $\begin{array}{l}\text { MRSA ATCC } 43300 \\
\text { MRSA-S1 } \\
\text { MRSA-2 } \\
\text { S. aureus ATCC33862 }\end{array}$ & $\begin{array}{l}200 \mu \mathrm{g} / \mathrm{mL} \\
200 \mu \mathrm{g} / \mathrm{mL} \\
200 \mu \mathrm{g} / \mathrm{mL} \\
100 \mu \mathrm{g} / \mathrm{mL}\end{array}$ & $\begin{array}{l}\text { Pro: Anti- staphylococcal } \\
\text { biofilm activity }\end{array}$ & Al Atya et al., 2016 \\
\hline TA6 & Pseudomonas aeruginosa TA6 & $\|$ & MRSA & ${ }^{*} \mathrm{ND}$ & & Arumugam et al., 2019 \\
\hline Pentocin JL-1 & Lactobacillus pentosus & । & MRSA GIM 1.771 & $7.5 \mu \mathrm{g} / \mathrm{mL}$ & $\begin{array}{l}\text { Pro: Active against gram } \\
\text { positive and gram negative } \\
\text { bacteria } \\
\text { Active against multi drug } \\
\text { resistant bacteria }\end{array}$ & Jiang et al., 2017 \\
\hline DS-3 & Brevibacillus latersporus & ${ }^{*} N D$ & $\begin{array}{l}\text { MRSA } \\
\text { S. aureus ATCC29212 } \\
\text { S. aureus ATCC } 25923\end{array}$ & ${ }^{*} \mathrm{ND}$ & & Odah et al., 2019 \\
\hline
\end{tabular}




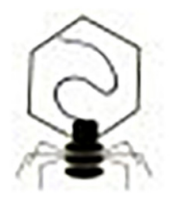

Aowninioe

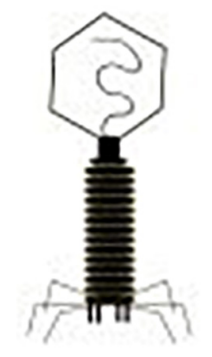

Mowise

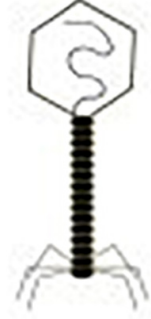

Sphovist
FIGURE 5 | Morphology of podoviridae, myoviridae, and siphoviridae phages (Newstead et al., 2020).
DNA genomes and consist of the Podoviridae, Siphoviridae and Myoviridae families of tailed phages (See Figure 5) (Ackermann, 2011). The families of Siphoviridae and Myoviridae represent most of the lytic phage community (Ackermann, 2011). Myoviridae phages differ from Siphoviridae phages by having a larger capsid head and contractile tails. Podoviridae phages have a different morphology with a capsid head that can be isometric, prolate or elongated and short non-contractile tails (Ackermann, 2011). In terms of potential use as an anti-S. aureus therapeutic, Myoviridae phages have demonstrated an impressive ability to target MRSA cells. Lytic phages from the Myoviriade family have been shown to have a broad host range, not only capable of infecting various staphylococcal species but also coagulase-negative species (CoNS) (O'Flaherty et al., 2004; Cui et al., 2012; Melo et al., 2018). Examples of such phages include SA012, K and 812 (Xia et al., 2011; Li et al., 2015; Fujiki et al., 2018).

Phages have been shown to be highly effective in the treatment of some bacterial infections (Wittebole et al., 2014), including infections caused by antibiotic resistant bacteria (Kortright et al., 2019). "Phage therapy" in general describes the use of phages, preferably lytic, to treat bacterial infections. One of the major advantages of phage therapy is that phages are highly specific and have narrow inhibition spectra, thus the target bacterium can be killed while the surrounding microbiota remain untouched. Bacteria are known to harbor phage resistance mechanisms including adsorption inhibition, restriction modification, abortive infection, the CRISPR-Cas system, and BREX, which can disrupt the phage lytic cycle at various stages (Lenski, 1988; Coffey and Ross, 2002; Labrie et al., 2010). Phages can evolve to evade these mechanisms but likewise, bacteria too can evolve to counter attack, resulting in defense and counter-defense cycles. However, the use of phage cocktails (two or more phages) can reduce the likelihood of bacterial resistance development ( $\mathrm{Gu}$ et al., 2012). Indeed, phage cocktails tend to be the treatment of choice and can be "updated" with specific phages in response to a particular infection, often resulting in personalized treatments. Further to this, it is important to point out that the development of phage resistance in the target bacterium can reduce its fitness and even pathogenicity (León and Bastías, 2015).

As previously discussed, S. aureus strains are capable of efficiently forming biofilms. This creates a significant obstacle when treating $S$. aureus infections, particularly MRSA. Phages have demonstrated an impressive ability to eradicate biofilms when compared with antibiotics (Azeredo and Sutherland, 2008). The cells present in a biofilm are enveloped in an extracellular polymeric substance (Archer et al., 2011). In contrast to antibiotics, some phages can gain access to the bacteria deep within a biofilm due to their production of polysaccharide depolymerase enzymes which break down the extracellular polymeric matrix (de Vries, 2019). Furthermore, phage concentrations increase with the lytic cycle - thus, as phages begin to target exterior layers of the biofilm, more phages are produced that can infect bacterial cells found deeper within the biofilm in a continuous cycle ultimately leading to full eradication as depicted in Figure 6; Clokie et al. (2011).

Phage adsorption to the host cell is the first step in phage infection. Cell wall teichoic acids (WTAs) are glycopolymers that are critical to cell division and are conserved in all $S$. aureus strains (Peng et al., 2019). WTAs can serve as phage receptors on the cell wall of Gram positive bacteria, allowing most $S$. aureus phages to bind (Figure 7; Pollack and Neuhaus, 1994; Meredith et al., 2008). In most cases, WTAs present on S. aureus cells are comprised of 1,5-ribitol-phosphate (RboP) repeats with the addition of D-alanine and a GlcNAc residue. The initiation of WTA biosynthesis begins by GlcNAc binding to undecaprenol lipids, a process mediated by TarO, an $\mathrm{N}$-acetylglucosamine transferase. The $\beta$-GlcNAc transferase, TarS, and $\alpha$-GlcNAc transferase, TarM, are responsible for the transfer of $\alpha$ - and $\beta$ linked GlcNAc onto WTA (Xia et al., 2010; Brown et al., 2012). WTAs are then transferred to the extracellular surface of the host cell where linking to peptidoglycan (PG) takes place (Estrella et al., 2016). However, some phages take advantage of alternative host cell wall components for mediation of binding. For example, the S. aureus-infecting phage Siphoviridae SLT uses lipoteichoic

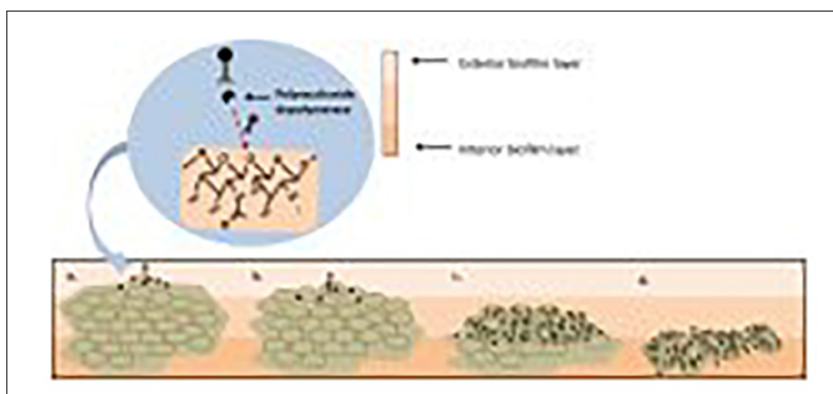

FIGURE 6 | (a) Initial biofilm exposure to proteins produced by the phage such as polysaccharide depolymerase. (b) Breakdown of the extracellular polymer substance allows for phage to infect the bacterial cells. (c) Phage infection of the bacterial cells in the exterior layer of the biofilm leads to infection of bacterial cells deeper within the biofilm. (d) A combination of the breakdown of the extracellular polymer substance due to polysaccharide depolymerase exposure and phage replication leads to the eradication of the biofilm. (Gutiérrez et al., 2016). 


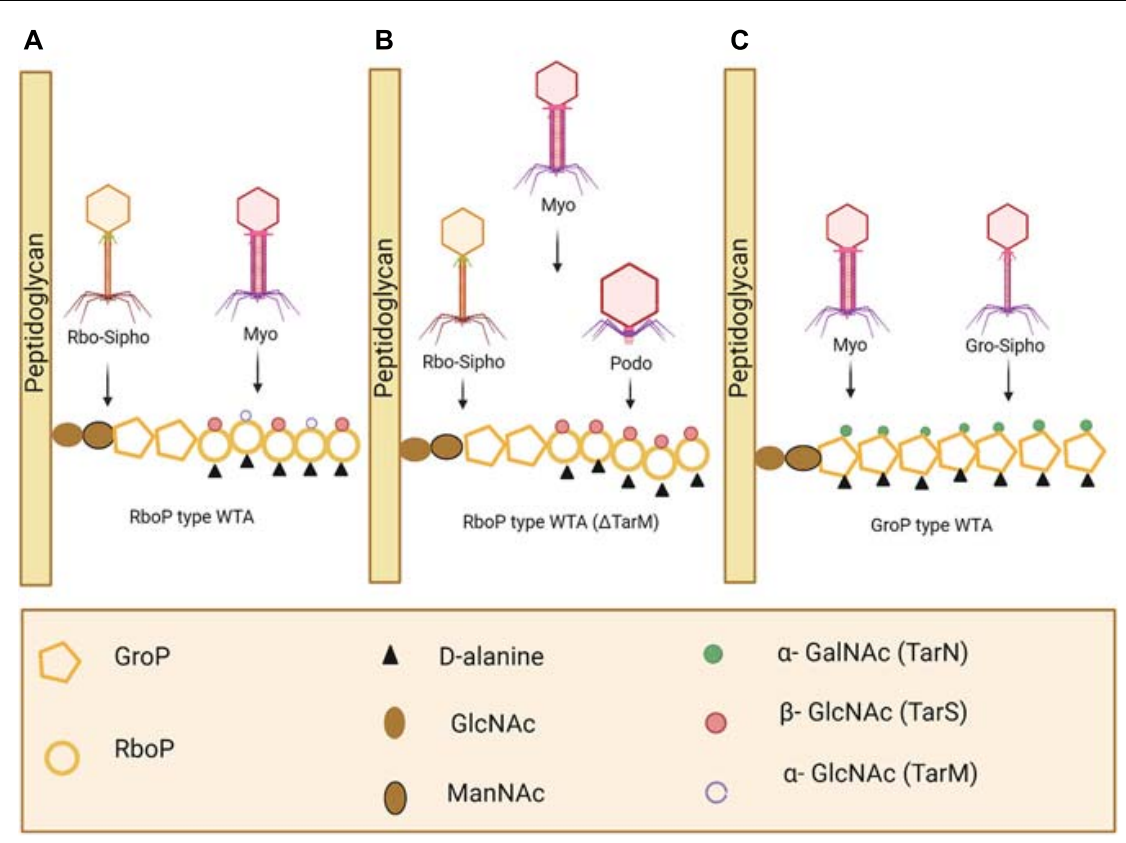

FIGURE 7 | Staphylococcus aureus phage recognition of wall teichoic acids (WTA) in Staphyococcus. (A) Staphylococcal Myoviridae (Myo) and S. aureus Siphoviridae (Rbo-Sipho) phages can recognize $\alpha$-GlcNAc and $\beta$-GlcNAc residue containing ribitol phosphate (RboP)-type WTA. (B) Podoviridae, Siphoviridae and Myoviridae phages are capable of infecting S. aureus when $\alpha$-GlcNAc residues are absent. (C) Glycerol phosphate (GroP)-type WTA is only recognized by Myoviridae phages and Gro-Siphoviridae phages (including CoNS and S. pseudointermedius phages) (Azam and Tanji, 2019). Created using Biorender.com.

acid (LTA) to bind to the host cell and carries the PVL toxin (Kaneko et al., 2009). A recent study reported on the presence of prophages with genes capable of encoding a different WTA glycosyltransferase, in many MRSA strains. TarP mediates the delivery of $\beta$-GlcNAc to an alternative RboP WTA hydroxyl group, in comparison to TarS. Due to the necessary presence of $\beta$ GlcNAc for phage infection to occur, this alternative route for $\beta$ GlcNAc allows for the bacterial cell to avert phage adsorption and subsequently phage infection (Gerlach et al., 2018). Considering the large number of MRSA strains in which this pathway has been observed, using phages that target the $\beta$-GlcNAc residue present in WTA no longer seems a logical choice for phage therapy. As depicted in Figure 7, S. aureus possesses various phage recognition WTAs.

\section{Limitations to Phage Therapy}

Despite all the aspects of phage therapy that showcase its potential as a therapeutic in human health, there are some limitations. As is the case with bacteriocins, the narrow spectrum of activity of phages is not always beneficial. However, this is overcome by the use of phage cocktails targeting a variety of specific hosts (Royer et al., 2021). Phages may invoke an immune response upon administration which has led to anaphylactic shock or hypersensitivity reactions (Gorski et al., 2012). The ability of phages to transfer genetic material such as virulence or antibiotic resistance genes to the host adds to the problem of antibiotic resistant bacteria (Modi et al., 2013). The lack of uptake in using phage therapy as a frontline therapeutic in western medicine is in part due to the fact that until recently the safety of this form of therapy has been largely unexplored (Lin et al., 2017), but is predominantly due to the difficulty in developing phage therapies that slot into existing regulatory frameworks (Sybesma et al., 2018). Indeed, updating phage cocktails/treatments with suitable phages in response to specific infections is essential if phage therapy is to fully work. However, under current regulatory frameworks, this represents a timely ordeal requiring preclinical, clinical and pharmaceutical documentation. Furthermore, the familiarity that many practitioners have with traditional antibiotic treatment, may pose a threat to the success of phage therapy (Sybesma et al., 2018).

\section{In vitro and in vivo Experiments of Phages Against MRSA}

Numerous in vitro and in vivo studies have reported the potential of phages and their lysins to eradicate MRSA infection (as seen in Table 3) (Schmelcher and Loessner, 2021). In vitro studies performed on phage Henu2 showed that alone this phage exhibits unimpressive inhibitory action against S. aureus. However, in combination with oxides or antibiotics, the phage is capable of a 3-log reduction in bacterial load within $24 \mathrm{~h}$ (Li et al., 2021). The ability of a phage to inhibit MRSA infection of skin wounds in a murine model was investigated by Ji et al. (2020). Infection was induced by subcutaneous injection of the MRSA strain, and following $1 \mathrm{~h}$, phage VB_SauS_SHSt was administered. An increased inflammatory response was observed in the untreated group, with the treated group experiencing faster wound rehabilitation and reduced tissue damage (Ji et al., 2020). A rat model was used to determine the efficacy of 
TABLE 3 | Examples of Phage and phage endolysins active against $S$. aureus

\begin{tabular}{|c|c|c|c|c|c|}
\hline Phage & Lysin & Family & S. aureus target & Inhibitory potential & References \\
\hline & PlySs2 & & $\begin{array}{l}\text { MRSA } 8325 \\
\text { MRSA MW2 }\end{array}$ & $\begin{array}{l}\text { MIC }-16 \mu \mathrm{g} / \mathrm{mL} \\
\mathrm{MIC}-16 \mu \mathrm{g} / \mathrm{mL}\end{array}$ & Gilmer et al., 2013 \\
\hline & Staphefekt SA.100 & & $\begin{array}{l}\text { Active against } 28 \text { MSSA strains and } 8 \text { MRSA } \\
\text { strains }\end{array}$ & $\mathrm{MIC}-64 \mu \mathrm{g} / \mathrm{mL}$ & Herpers et al., 2016 \\
\hline \multirow[t]{4}{*}{ Phage K } & & Myoviridae & Active on 39 of 53 MRSA isolates tested & & O'Flaherty et al., 2005 \\
\hline & LysK & & MRSA USA300 & MIC - 650nM & Becker et al., 2008 \\
\hline & CHAPk & & MRSA 252 & MIC $-0.125 \mu \mathrm{g} / \mathrm{mL}$ & Hathaway et al., 2017 \\
\hline & SAL200 & & MRSA & $\begin{array}{l}\text { Treatment protected } 95-100 \% \text { of mice compared to } \\
40-93 \% \text { of mice that died in the control group }\end{array}$ & Bae et al., 2019 \\
\hline $\mathrm{MH}-1$ & & Myoviridae & Active on 27 of 30 MRSA isolates tested & & Hallajzadeh et al., 2020 \\
\hline MR003 & & Myoviridae & Active on 26 out of $28 \mathrm{MRSA}$ isolates tested & & Peng et al., 2019 \\
\hline 812 & & Myoviridae & $43 \%$ of 89 CoNS S. aureus isolates tested & & Pantůček et al., 1998 \\
\hline Sb-1 & & Myoviridae & Active on 22 of $28 \mathrm{MRSA}$ isolates tested & & Tkhilaishvili et al., 2018 \\
\hline ISP & & Myoviridae & Active on $86 \%$ of MRSA isolates tested & & Vandersteegen et al., 2011 \\
\hline $\begin{array}{l}\text { Stafal (Commercial } \\
\text { Preparation of phages) }\end{array}$ & & Myoviridae & $\begin{array}{l}\text { S. aureus SF29 (MRSA) } \\
\text { S. aureus SF34 (MRSA) } \\
\text { S. aureus SF92 (MRSA) } \\
\text { S. aureus SF121 (MRSA) } \\
\text { S. aureus SF123 (MRSA) }\end{array}$ & $\begin{array}{l}10^{8} \mathrm{PFU} / \mathrm{mL} \text { of phage eradicated biofilms of all strains } \\
\text { following } 24 \mathrm{~h} \text { treatment }\end{array}$ & Dvořáčková et al., 2019 \\
\hline $\mathrm{SCH} 1$ & & Podoviridae & Active on $97 \%$ of $31 \mathrm{MRSA}$ isolates tested & & Azam and Tanji, 2019 \\
\hline B1 & & Myoviridae & Active on $73.9 \%$ of 23 S. aureus isolates & & Ajuebor et al., 2018 \\
\hline \multirow[t]{2}{*}{ VB_SauS_SH-St } & & Siphoviridae & Active on $32 \%$ of MRSA isolates tested & & Ji et al., 2020 \\
\hline & Lys109 & & S. aureus CCARM 3090 & $\mathrm{MIC}-0.375 \mu \mathrm{M}$ & Son et al., 2021 \\
\hline $\mathrm{JA} 1$ & & Myoviridae & Active on $78.2 \%$ of $23 \mathrm{~S}$. aureus isolates & & Ajuebor et al., 2018 \\
\hline Henu2 & & Siphoviridae & Active on $54 \%$ of MRSA isolates tested & & Li et al., 2021 \\
\hline \multirow[t]{3}{*}{ MR11 } & & Siphoviridae & $\begin{array}{l}\text { S. aureus SA37 } \\
\text { MRSA strains MR1, } \\
\text { MR13, MR18, or MR28 }\end{array}$ & $\begin{array}{l}\text { MOI of } 1 \text { protected mice } \\
\text { MOI of } 50 \text { protected mice up to } 7 \text { days after treatment }\end{array}$ & Matsuzaki et al., 2003 \\
\hline & MV-L & & MRSA 85/2082-STR1 & $\begin{array}{l}\text { MV-L administered directly after }(n=10) \text { or } 30 \text { minutes } \\
(n=10) \text { after infection rescued } 100 \% \text { of mice }\end{array}$ & Rashel et al., 2007 \\
\hline & GP16 & & Active on 22 S. aureus isolates tested & & Rashel et al., 2007 \\
\hline$M^{S a}$ & & & $\begin{array}{l}\text { S. aureus A170 } \\
\text { S. aureus A352 (MRSA) }\end{array}$ & $\begin{array}{l}\text { Rescued } 97 \% \text { of Mice }(n=5) \\
\text { Rescued } 100 \% \text { of mice }(n=5)\end{array}$ & Capparelli et al., 2007 \\
\hline \multirow[t]{2}{*}{ SA012 } & & Myoviridae & Active on 21 of $28 \mathrm{MRSA}$ isolates & & Peng et al., 2019 \\
\hline & Lys-SA012 & & $\begin{array}{l}\text { S. aureus 2007-13 (MRSA) } \\
\text { S. aureus 2007-28 (MRSA) } \\
\text { S. aureus 2007-57 (MRSA) } \\
\text { S. aureus 2007-93 (MRSA) } \\
\text { S. aureus VC39-Vet1 (MRSA) S. aureus } \\
\text { VC50-Vet1 (MRSA) }\end{array}$ & Active on all MRSA isolates tested & Fujiki et al., 2018 \\
\hline
\end{tabular}




\begin{tabular}{|c|c|c|c|c|c|}
\hline $\begin{array}{l}\text { TABLE } 3 \\
\text { Phage }\end{array}$ & & Family & & & \\
\hline R4 & & Siphoviridae & Active on 14 MRSA strains tested & & Pertics et al., 2020 \\
\hline MR-5 & & Myoviridae & Active against $18 / 45$ clinical MRSA isolates & & Kaur et al., 2012 \\
\hline MR-10 & & Myoviridae & S. aureus ATCC 43300 (MRSA) & $3.5 \mathrm{log}$ reduction on day $3(n=12)$ & Chhibber et al., 2013 \\
\hline ME18 & & Myoviridae & $\begin{array}{l}\text { S. aureus 1S (MRSA) } \\
\text { S. aureus } 8 \text { ( MRSA) } \\
\text { S. aureus 6M (MRSA) } \\
\text { S. aureus 12M (MRSA) }\end{array}$ & MOl of 10 significantly reduced biofilm in all strains & Gharieb et al., 2020 \\
\hline \multirow[t]{2}{*}{ ME126 } & & Myoviridae & $\begin{array}{l}\text { S. aureus 1S (MRSA) } \\
\text { S. aureus } 8 \text { ( MRSA) } \\
\text { S. aureus 6M (MRSA) } \\
\text { S. aureus 12M (MRSA) }\end{array}$ & MOl of 10 significantly reduced biofilm in all strains & Gharieb et al., 2020 \\
\hline & CF-301 & & $\begin{array}{l}\text { S. aureus Newman } \\
\text { S. aureus MW2 } \\
\text { S. aureus CFS-1246 } \\
\text { S. aureus VRS3a }\end{array}$ & MBEC- $\leq 0.25 \mu \mathrm{g} / \mathrm{ml}$ & Schuch et al., 2017 \\
\hline UPKM_1 & & Siphoviridae & Active against 19 of $25 \mathrm{MRSA}$ isolates & & Dakheel et al., 2019 \\
\hline UPKM_2 & & Podoviridae & Active against 22 of $25 \mathrm{MRSA}$ isolates & & Dakheel et al., 2019 \\
\hline GH15 & LysGH15 & Myoviridae & S. aureus YB57 (MRSA) & All mice were rescued by $50 \mu \mathrm{g}$ dose $(n=5)$ & Gu et al., 2011 \\
\hline \multirow[t]{2}{*}{ SAP-2 } & & Podoviridae & Active against 5 out $10 \mathrm{~S}$. aureus strains tested & & Son et al., 2010 \\
\hline & SAL-2 & & $\begin{array}{l}\text { Active against 100\% (10) of S. aureus strains } \\
\text { tested against. } \\
\text { Including MRSA }\end{array}$ & MIC $-1 \mu \mathrm{g} / \mathrm{mL}$ for MRSA isolates & Son et al., 2010 \\
\hline 131 & & & $\begin{array}{l}\text { Active against } 69 \% \text { of } 120 \text { MRSA isolates } \\
\text { tested }\end{array}$ & & Pantucek et al., 2013 \\
\hline U16 & & & $\begin{array}{l}\text { Active against } 65 \% \text { of } 120 \text { MRSA isolates } \\
\text { tested }\end{array}$ & & Pantucek et al., 2013 \\
\hline SK311 & & & $\begin{array}{l}\text { Active against } 52 \% \text { of } 120 \text { MRSA isolates } \\
\text { tested }\end{array}$ & & Pantucek et al., 2013 \\
\hline \multirow[t]{2}{*}{ Stau2 } & & Myoviridae & $\begin{array}{l}\text { S. aureus S23 } \\
\text { S. aureus CS38 (MRSA) } \\
\text { S. aureus KS7 (MRSA) } \\
\text { S. aureus TS21 (MRSA) }\end{array}$ & $\begin{array}{l}\text { Phage at an } \mathrm{MOl} \text { of } 10 \text { administered immediately } \\
\text { rescued } 100 \% \text { mice }(n=5) \\
\text { Reduced } \mathrm{OD}_{600} \text { to nearly } 0 \text { after } 3 \mathrm{~h} \\
\text { Reduced } \mathrm{OD}_{600} \text { to nearly } 0 \text { after } 3.5 \mathrm{~h} \\
\text { Reduced } \mathrm{OD}_{600} \text { to nearly } 0 \text { after } 3 \mathrm{~h}\end{array}$ & Hsieh et al., 2011 \\
\hline & Lys109 & & $\begin{array}{l}\text { S. aureus CCARM } 3090 \\
\text { S. aureus RN4220 }\end{array}$ & $\begin{array}{l}3 \text { fold reduction in biofilm formation compared to } \\
\text { SA012 (parental lysin) }\end{array}$ & Son et al., 2021 \\
\hline DMSA-2 & & Siphoviridae & S. aureus DSMA-2 (MRSA) & $\begin{array}{l}100 \% \text { of mice in treatment group survived compared to } \\
34 \% \text { in the untreated group }\end{array}$ & Shetru et al., 2021 \\
\hline
\end{tabular}

$3.5 \log$ reduction on day $3(n=12)$

Pertics et al., 2020

of 25 MRSA isolates

S. aureus YB57 (MRSA)

tested against.

tested

tested

tested

S. aureus CS38 (MRSA)
S. aureus KS7 (MRSA) 
a recombinant nano phage in treating MRSA ATCC 33591infected $3^{\text {rd }}$ degree wounds. The wounds which received topical application of the phage demonstrated a more efficient healing process (Rahimzadeh et al., 2020). Shetru et al. (2021) also investigated the ability of phage DSMA-2 to reduce $S$. aureus infection of a skin wound. This study examined multiple groups of mice treated with various concentrations of the phage. Phage treatment improved wound healing and tissue remodeling, while also rescuing $100 \%$ of the mice from death at a phage concentration of $5 \times 10^{6} \mathrm{pfu} / \mathrm{mL}$ compared with a $34 \%$ survival rate in the untreated group.

\section{Clinical Uses of Phages Against MRSA}

The use of phage therapy in humans has mostly occurred in Eastern Europe and the former Soviet Union. In these cases, antibiotics may still be used as a first defense; however, upon failure to eradicate an infection, follow-up phage treatment has shown impressive results. Most studies reporting on the efficacy of phage treatment for bacterial infections report an $\sim 85 \%$ success rate (O'Flaherty et al., 2009). Although some studies have investigated the response of the immune system to phage treatment, results have been conflicting. For example, studies have reported that circulating phages in the blood elicit the innate immune system, while other studies have observed the ability of phages to go undetected by the immune system (Capparelli et al., 2007). Despite these conflicting results, clinical trials are underway with phages. Nine participants took part in a Phase I clinical trial, to examine the effect of the phage cocktail ABSA01 on patients with recalcitrant chronic rhinosinusitis (Ooi et al., 2019). The results indicated the phage cocktail was well tolerated by patients with eradication of infection in two of the nine participants (Ooi et al., 2019).

Studies have also been published which describe the use of phage therapy as a compassionate treatment. The focus of compassionate treatment is not to provide results to evaluate the efficacy of the treatment but rather to benefit the patient when no other options are available. These case studies involving phage administration have indeed provided insight into the effectiveness of phage therapy in humans. Interestingly, in such cases of compassionate treatment, the most frequently reported bacterial infection to target is that of $S$. aureus (McCallin et al., 2019). It is important to note that compassionate treatment is generally only approved once all other treatments have been exhausted. One such example is a case study of six diabetic patients who underwent compassionate phage treatment for poorly perfused toe ulcers infected with $S$. aureus (Fish et al., 2016). The infection was non-responsive to antibiotic treatment and so therapy with staphylococcal phage Sb-1 took place. In all cases, phage treatment was sufficient to eradicate the $S$. aureus cells. Another case study gives an account of two individuals who obtained radiation burns and subsequently developed $S$. aureus infections in their wounds (Jikia et al., 2005). Following antibiotic therapy, the infection persisted in both cases. PhageBioDerm is a preparation comprising a cocktail of lytic phages with various specific hosts, in a biodegradable polymer mixture. The phage preparation inhibited the growth of $S$. aureus and eradicated the infection. The administration of PhageBioDerm in this case study demonstrates the non-invasive manner in which phages can be used to treat infection, in this case, applied as a film to the surface of the skin ulcer.

Depending on the type of infection with which a patient is suffering, varying methods of phage treatment may be selected. An infection site with a mixed community of pathogenic bacteria would respond better if treated with a phage cocktail. When choosing the most effective strategy for phage therapy, phage cocktails are widely considered the superior approach, allowing for higher and more prolonged bactericidal activity. This method of treatment consists of using a mixture of various phages with the same or different target hosts, depending on the type of infection. This creates a greater obstacle for the bacteria in terms of developing resistance (Tanji et al., 2004; Chan et al., 2013). Phage cocktails can also be used in combination with antibiotics. However, in such cases, the order of administration between the phage and antibiotics has rendered differential effects on the outcome of the treatment. Kumaran et al. (2018) carried out a study in vitro investigating the synergistic effect of lytic phage SATA-8505 with various antibiotics to inhibit biofilmforming $S$. aureus cells. This study not only looked at the dual antimicrobial action of phages used in combination with antibiotics but also the order in which each therapeutic was administered. This study concluded that a treatment plan of phage therapy followed by antibiotic treatment proved the most effective at eradicating an $S$. aureus biofilm. Therefore, these results should be considered when designing a treatment plan involving both phage and antibiotic therapy (Abedon et al., 2011; Kumaran et al., 2018).

\section{PHAGE LYSINS}

\section{Background}

Phages encode peptidoglycan hydrolases - highly evolved enzymes known as lysins that mediate the release of phage particles from bacterial host cells (Fischetti, 2010) and thus act from the inside out. Phages also encode virion-associated peptidoglycan hydrolases (VAPGH) - enzymes that mediate the injection of phage DNA into the bacterial cell by creating a small hole in the cell (Keary et al., 2014). Most endolysins have at least two functional domains, the N-terminal domain (location of enzymatic activity) and the cell wall binding domain (ensures enzymes act on their substrates) (Loessner, 2005). Phage endolysins induce bacterial lysis in Gram positive bacteria leading to cell death (Loessner, 2005; Fenton et al., 2010b). There are many advantages to using phage endolysins over antibiotics. Phage endolysins are specific for their target; therefore, collateral damage to commensal organisms will not occur. With regards to resistance, there are no known MRSA strains to date with resistance to phage lysins given that resistant strains would need to fundamentally change the structure of their cell wall. This highlights a huge benefit to using phage lysins to combat bacterial infections (Loeffler et al., 2001; Loessner, 2005). Additionally, phage lysins are thought to have the ability to counter bacterial resistance by targeting certain molecules that are key to maintaining cell viability (Garcia et al., 1983; Fischetti, 
2010). The ability of phage lysins to infect and lyse MRSA strains have also been observed. Some examples of phage lysins eliciting such effects include phage endolysins MV-L (Rashel et al., 2007), Lys-SA012 (Fujiki et al., 2018), GH15 (Gu et al., 2011), PlySs2 (Gharieb et al., 2020), and LysK (O’Flaherty et al., 2005).

The development of lysins in recent years has come through three phases. $1^{\text {st }}$ generation lysins are natural lysins, which exhibit antimicrobial activity in their own right. An example of this is the phage lysin CF-301, produced by a Streptococcus suis prophage, which has demonstrated impressive anti-MRSA activity in vitro and in vivo (outlined below). CF301 is also the first phage lysin to reach a phase III clinical trial (NCT04160468) (outlined below). $1^{\text {st }}$ generation lysins were improved upon, with the use of protein engineering, to produce $2^{\text {nd }}$ generation lysins (De Maesschalck et al., 2020), the goal of which was to enhance biochemical components and antimicrobial activity. $3^{\text {rd }}$ generation lysins are developed with the aim of optimization for clinical treatment in humans. This involves using protein and biochemical engineering, as well as innovative formulations to improve aspects including halflife, bioavailability, immune response and antimicrobial activity (De Maesschalck et al., 2020).

It is essential that lysins do not invoke a significant immune response. Strategies used in lysin engineering to escape the host immune response include glycosylation, PEGylation and T-cell epitope depletion (De Maesschalck et al., 2020). One example of a lysin designed to evade immune recognition is PEGylated lysostaphin (Walsh et al., 2003). Lysostaphin is a bacterially produced lytic enzyme. While this technique reduced the activity of the enzyme in vitro, the half-life of the modified lysostaphin in vivo was increased to $24 \mathrm{~h}$ compared with a half-life of less than $1 \mathrm{~h}$ for the unconjugated lysostaphin. As well as that, binding affinities for antibodies to the PEGylated lysostaphin were reduced by 10 -fold compared with the unconjugated version. Reducing an immune response to lysins can also be achieved by formulations of lysins incorporated with anti-inflammatory compounds (Cheng et al., 2018). Due to the effect of renal filtration on the half-life of lysins, strategies that directly target this filtration process have been developed to improve lysin halflife. One strategy involves increasing hydrodynamic volume, by fusion of the chosen lysin and a water-binding polymer (Turecek et al., 2016). The lysin can also be dimerized in an attempt to reduce filtration (Grishin et al., 2019). While both these approaches did succeed in extending the half-life of the lysin, in both cases antimicrobial activity was negatively affected.

\section{Limitations to Phage Lysins}

Lysins typically have a short half-life, this is due to glomerular filtration which is a system that removes small proteins $(<40$ $50 \mathrm{kDa}$ ) from the body (De Maesschalck et al., 2020). This results in the majority of the lysin being excreted and subsequently unable to act on any infection present. Lysins are foreign proteins entering the host and so a pro-inflammatory response will be induced, involving production of anti-lysin antibodies (Schmelcher and Loessner, 2021). With the ability of S. aureus to persist inside eukaryotic cells, the inability of phage and most phage lysins to reach intracellular compartments of these eukaryotic cells makes complete eradication of the infections difficult (Schmelcher and Loessner, 2021). The majority of shortcomings of lysin treatment outlined above have been overcome or developed upon by the manufacturing of 2nd and 3rd generation lysins (discussed above).

\section{In vitro and in vivo Experiments of Phage Lysins Against MRSA}

Nakamura et al. (2020) investigated the action of both phage phiSA012 and its lysin Lys-phiSA012 against multidrug-resistant staphylococcal isolates of canine origin. While the ability of the phage to lyse the staphylococcal isolates was not significant, the lytic activity of the lysin was far more impressive. Lys-phiSA012 lysed all multi drug resistant staphylococcal isolates except one, compared to the 4 multi drug resistant strains PhiSA012 was active against. Lys 109 is a chimeric lysin with anti-staphylococcal activity. Crystal violet staining was used to examine the biofilminhibitory activity of the lysin, which reduced S. aureus CCARM 3090 and S. aureus RN4220 biofilms by 3-fold compared to its parental lysin SA012. At a concentration of $1000 \mathrm{nM}$ Lys109 reduced the OD570 of the S. aureus CCARM 3090 and S. aureus RN4220 biofilms from 1 (control) to $<0.2$ in both cases (Son et al., 2021). CF-301 has also demonstrated impressive antibiofilm activity in vitro. One study exhibited the ability of CF301 to inhibit the growth of an S. aureus BAA-42 (MRSA) biofilm. This ability was further exhibited by the eradication of biofilms grown in synovial fluid and human blood, as well as biofilms grown under specific conditions favoring the growth of persistent S. aureus cells (Schuch et al., 2017). Another in vitro study used phage lysin to enhance a spider silk-based coating developed for orthopaedic and dental implants. The hypothesis is that this coating enhanced with Dispersin B and CF-301 or SAL1 will be able to reduce adhesion of bacteria causing common biomaterial-associated infection of orthopaedic and dental implants. The enhanced spider silk-based coating dramatically reduced attachment of bacteria and subsequent formation of biofilms (Nilebäck et al., 2019).

As previously discussed, $S$. aureus infection can take place at various locations throughout the body. This in itself leads to a variety of challenges in terms of the best route of delivery. Various in vivo studies have investigated the effects of phage endolysins on infections in a variety of locations throughout the body. The phage lysin CF-301 has shown impressive results for treating endocarditis and bloodstream infections in vivo (Schmelcher and Loessner, 2021). This lysin has also worked synergistically with a variety of antibiotics (Watson et al., 2020). Indiani et al. (2019) carried out a study utilizing a combination of CF-301 and daptomycin to treat endocarditis in rabbits. Treatment reduced the bacterial load of MRSA surrounding the heart by 6 logs. CF301 has also been used to treat osteomyelitis, an infection of the bone commonly caused by S. aureus (Ellington et al., 2006). One week following infection, CF-301 and a combination of CF-301 and daptomycin were administered to rats intravenously. CF-301 did not remarkably reduce the bacterial load (0.48 logs), however, the combination treatment achieved slightly better results with a $1.56 \mathrm{log}$ reduction in bacterial load (Karau et al., 2019). SAL200 is an endolysin produced by staphylococcal phage. The ability of SAL200 to treat MRSA-associated pneumonia in a mouse 
model has been investigated. The endolysin rescued $95-100 \%$ of mice following infection, whereas $40-93 \%$ of the control group died following $60 \mathrm{~h}$ of infection (Bae et al., 2019). Aquaphor gel was used to incorporate the lysin LysGH15 and apigenin, forming a LysGH15-api-Aquaphor ointment (Cheng et al., 2018). Apigenin is a plant-derived flavonoid with anti-inflammatory properties, which has been shown to reduce negative effects, such as hemolysis, caused by $S$. aureus infection in rabbits (De Maesschalck et al., 2020). This treatment improved healing of skin wounds in a murine model, while also decreasing levels of inflammatory cytokines IL- $1 \beta$, TNF- $\alpha$ and IFN- $\gamma$ (Cheng et al., 2018).

As described above, the ability of lysins to act on pathogenic bacteria present within eukaryotic cells is important for the inhibition of S. aureus. Becker et al. (2016) developed a $3^{\text {rd }}$ generation lysin engineered to inhibit intracellular S. aureus. Two parental proteins (LysK and lysostaphin) were fused to generate a recombinant protein with 3 antimicrobial activities. This fusion protein significantly reduced nasal colonization of S. aureus in a rat model (98\% reduction), out-performing both parental proteins. The fusion protein was enhanced by addition of a protein transduction domain, which increased both inhibition of $S$. aureus biofilm as well as intracellular $S$. aureus in vivo (Becker et al., 2016). Röhrig et al. (2020) also used cell-penetrating peptide (CPP) activity to enhance selected lysins and deliver their antimicrobial action to intracellular compartments. This was achieved by the addition of a trans-activating transcription (tat) factor derived-CPP, which led to an intracellular MRSA reduction of up to $4.5 \mathrm{logs}$ in various cells lines (A549, 3T3L1, and MG-63) and more than $2.2 \log$ reductions in a murine model with cutaneous abscesses (Röhrig et al., 2020). The phage lysin JDlys, produced by staphylococcal phage JD007, exhibited impressive anti-MRSA activity and so a study was performed to enhance the ability of JDlys to inhibit intracellular MRSA. Similar to the study just mentioned, tat factor-derived-CPPs were used for the enhancement of the lysin. This newly formed complex significantly reduced the presence of MRSA USA300 cells in $\mathrm{HaCaT}$ keratinocytes. This result was also achieved in a cutaneous abscess-induced mouse model, in which the CPP-JDlys protein reduced both bacterial load of the wound as well as the inflammatory response (Wang et al., 2018).

\section{Clinical Uses of Phage Lysins Against MRSA}

SAL200 has shown promising results for treatment of blood stream infections, having already undergone studies to examine pharmacokinetics and safety in humans and pre-clinical characterization (NCT01855048) (Jun et al., 2017). SAL200 is currently in a Phase II clinical trial for treatment of blood stream infections (NCT03089697). Phage lysin CF-301 was used to treat endocarditis and blood stream infections in a Phase II clinical trial (NCT03163446). The study focused on cases of these diseases caused by $S$. aureus, with a subgroup of MRSA infection. Treatment solely with antibiotics was compared with a combination treatment of CF-301 and antibiotics. Combination treatment of individuals with MRSA infection resulted in a
$74.1 \%$ response rate, compared to a response rate of $31.3 \%$ from antibiotic treatment alone (Fowler et al., 2020). CF-301 is currently undergoing a phase III clinical trial, in which CF301 treatment of blood stream infections and endocarditis is being compared with antibiotic treatment in terms of efficacy and safety (NCT04160468). A biotechnology company, Micreos, has paved the way for the development of endolysin-centered products for human health by launching the brand Gladskin in 2019 (Herpers et al., 2016). One of their products is a recombinant endolysin, called Staphefekt SA.100, which when topically applied to the skin has been shown to dramatically reduce $S$. aureus infection and associated inflammation in patients (Totte et al., 2017). Staphefekt is, to date, the only commercially available phage preparation and is recognized in Europe as a Class I medical device which is available over the counter as a cetomacrogol-based gel or cream. The ability of the lysin to remain stable while also exhibiting such effective antimicrobial activities demonstrates potential for further development as a therapeutic for human health. A clinical trial examining the effect of Staphefekt on atopic dermatitis was recently performed (NCT02840955). The results of the twelve-week treatment showed that Staphefekt was well tolerated by patients (de Wit et al., 2019). Endolysin XZ.700, which is active against $S$. aureus, is a product that is also being developed by Micreos which has undergone pre-clinical trials (Herpers et al., 2016) and has successfully moved onto phase I/IIa clinical trial (NL8876).

\section{CONCLUSION}

Staphylococcus aureus infections continue to be a challenge in hospital settings, particularly MRSA. This environment is primed for rapid infection spread due to the compromised immune response of patients and a large overlap between personnel and patient contacts. This is compounded by the phenotypic behavior of $S$. aureus and their propensity for forming biofilms on surgical equipment and colonizing open wounds in the skin. The rate at which bacterial strains and particularly staphylococci are developing immunity or resistance to antimicrobials is a major concern. New antibiotics are not being developed fast enough to counteract the antibiotic resistance crisis, with several existing antibiotics becoming ineffective in clinical practice (Field et al., 2016). Thus, development of antibiotic alternatives such as bacteriocins, phages and their endolysins are urgently needed to curb this increase in antibiotic resistance spread. The non-invasive manner in which these therapeutics can be applied, topically in a gel or cream form, adds to the attraction of using them to treat bacterial infections. When compared to antibiotics, bacteriocins and phages generally have narrow inhibition spectra, thus are target-specific, representing ideal therapeutics in an era when the importance of the microbiome to human health is being realized. Furthermore, due to their geneencoded nature, bacteriocins can be bioengineered to produce variants with enhanced abilities. To date, bacteriocins such as nisin are being used for food safety and preservation purposes. However, it is envisaged that future bacteriocin research will 
focus on their development to treat infections in humans. This could focus on the synergistic effects of bacteriocins with antibiotic therapy, as well as innovative ways of administering bacteriocins to humans. Phage therapy is already established in certain parts of the globe but to gain acceptance in western medicine it will require more randomized controlled clinical trials and perhaps a new regulatory framework that can take full advantage of the potential that phage therapy has to offer. Phage endolysins are phage-derived enzymes and like their progenitor are target-specific. While bacterial cells can develop resistance to endolysins, resistance against currently developed endolysins for MRSA has not been documented, suggesting it is a challenging feat for the bacterial cell. Although there are limitations to both bacteriocin and phage therapy, these obstacles are being challenged by nanotechnology incorporated bacteriocins and $2^{\text {nd }}$ and $3^{\text {rd }}$ generation lysins. Going forward, phage- and bacteriocinbased therapies possess potential for the development of novel therapeutics which can replace and even enhance some existing

\section{REFERENCES}

Abedon, S. T., Kuhl, S. J., Blasdel, B. G., and Kutter, E. M. (2011). Phage treatment of human infections. Bacteriophage 1, 66-85. doi: 10.4161/bact.1.2.15845

Acedo, J. Z., Van Belkum, M. J., Lohans, C. T., Towle, K. M., Miskolzie, M., and Vederas, J. C. (2016). Nuclear magnetic resonance solution structures of lacticin Q and aureocin A53 reveal a structural motif conserved among leaderless bacteriocins with broad-spectrum activity. Biochemistry 55, 733-742. doi: 10.1021/acs.biochem.5b01306

Ackermann, H. W. (2011). Bacteriophage taxonomy. Microbiol. Austral. 32, 90-94. doi: $10.1071 / \mathrm{ma} 11090$

Ahire, J. J., and Dicks, L. M. T. (2015). Nisin incorporated with 2, 3dihydroxybenzoic acid in nanofibers inhibits biofilm formation by a methicillin-resistant strain of Staphylococcus aureus. Probiot. Antimicrob. Proteins 7, 52-59. doi: 10.1007/s12602-014-9171-5

Ajuebor, J., Buttimer, C., Arroyo-Moreno, S., Chanishvili, N., Gabriel, E. M., O'mahony, J., et al. (2018). Comparison of Staphylococcus phage K with close phage relatives commonly employed in phage therapeutics. Antibiotics 7:37. doi: 10.3390/antibiotics7020037

Al Atya, A. K., Belguesmia, Y., Chataigne, G., Ravallec, R., Vachée, A., Szunerits, S., et al. (2016). Anti-MRSA activities of enterocins DD28 and DD93 and evidences on their role in the inhibition of biofilm formation. Front. Microbiol. 7:817. doi: 10.3389/fmicb.2016.00817

Ansari, A., Zohra, R. R., Tarar, O. M., Qader, S. A. U., and Aman, A. (2018). Screening, purification and characterization of thermostable, protease resistant Bacteriocin active against methicillin resistant Staphylococcus aureus (MRSA). BMC Microbiol. 18:192. doi: 10.1186/s12866-018-1337-y

Archer, N. K., Mazaitis, M. J., Costerton, J. W., Leid, J. G., Powers, M. E., and Shirtliff, M. E. (2011). Staphylococcus aureus biofilms: properties, regulation, and roles in human disease. Virulence 2, 445-459. doi: 10.4161/viru.2.5.17724

Arumugam, T., Dhanam, S., Rameshkumar, N., Krishnan, M., and Kayalvizhi, N. (2019). Inhibition of methicillin resistant Staphylococcus aureus by bacteriocin producing Pseudomonas aeruginosa. Int. J. Peptide Res. Ther. 25, 339-348. doi: 10.1007/s10989-018-9676-y

Aunpad, R., and Na-Bangchang, K. (2007). Pumilicin 4, a novel bacteriocin with anti-MRSA and anti-VRE activity produced by newly isolated bacteria Bacillus pumilus strain WAPB4. Curr. Microbiol. 55, 308-313. doi: 10.1007/s00284-0060632-2

Azam, A. H., and Tanji, Y. (2019). Peculiarities of Staphylococcus aureus phages and their possible application in phage therapy. Appl. Microbiol. Biotechnol. 103, 4279-4289. doi: 10.1007/s00253-019-09810-2

Azeredo, J., and Sutherland, I. W. (2008). The use of phages for the removal of infectious biofilms. Curr. Pharm. Biotechnol. 9, 261-266. doi: 10.2174/ 138920108785161604 antimicrobial therapies which are currently failing in the light of the antibiotic resistance crisis.

\section{AUTHOR CONTRIBUTIONS}

LW conceived and wrote the first draft of the manuscript. CJ, $\mathrm{CH}$, and $\mathrm{PR}$ reviewed and contributed to the final manuscript. All authors contributed to the article and approved the submitted version.

\section{FUNDING}

This publication has emanated from research conducted with the financial support of Science Foundation Ireland (SFI) under Grant Number SFI/12/RC/2273_P2 (APC Phase 2 center grant number APC18753 - Theme 1.1 Microbes to Molecules).

Bae, J. Y., Jun, K. I., Kang, C. K., Song, K.-H., Choe, P. G., Bang, J.-H., et al. (2019). Efficacy of intranasal administration of the recombinant endolysin Sal200 in a lethal murine Staphylococcus aureus pneumonia model. Antimicrob. Agents Chemother. 63:e02009-18.

Banerjee, R. (2001). Liposomes: applications in medicine. J. Biomater. Appl. 16, 3-21. doi: 10.1106/ra7u-1v9c-rv7c-8qxl

Bavin, E. M., Beach, A. S., Falconer, R., and Fried-Mann, R. (1952). Nisin in experimental tuberculosis. Lancet 1, 127-129. doi: 10.1016/s0140-6736(52) 92429-x

Becker, S. C., Foster-Frey, J., and Donovan, D. M. (2008). The phage K lytic enzyme LysK and lysostaphin act synergistically to kill MRSA. FEMS Microbiol. Lett. 287, 185-191. doi: 10.1111/j.1574-6968.2008.01308.x

Becker, S. C., Roach, D. R., Chauhan, V. S., Shen, Y., Foster-Frey, J., Powell, A. M., et al. (2016). Triple-acting lytic enzyme treatment of drug-resistant and intracellular Staphylococcus aureus. Sci. Rep. 6, 1-10.

Beller, F. K., and Schweppe, K. W. (eds) (1979). "Review on the biology of menstrual blood," in The Biology of the Fluids of the Female Genital Tract, (Amsterdam: Elsevier), 231-245.

Bengtsson, T., Lönn, J., Khalaf, H., and Palm, E. (2018). The lantibiotic gallidermin acts bactericidal against Staphylococcus epidermidis and Staphylococcus aureus and antagonizes the bacteria-induced proinflammatory responses in dermal fibroblasts. Microbiologyopen 7:e00606. doi: 10.1002/mbo3.606

Bonelli, R. R., Schneider, T., Sahl, H.-G., and Wiedemann, I. (2006). Insights into in vivo activities of lantibiotics from gallidermin and epidermin mode-of-action studies. Antimicrob. Agents Chemother. 50, 1449-1457. doi: 10.1128/aac.50.4. 1449-1457.2006

Brown, S., Xia, G., Luhachack, L. G., Campbell, J., Meredith, T. C., Chen, C., et al. (2012). Methicillin resistance in Staphylococcus aureus requires glycosylated wall teichoic acids. Proc. Natl. Acad. Sci. U.S.A. 109, 18909-18914. doi: 10.1073/ pnas.1209126109

Bruno, M. E. C., and Montville, T. J. (1993). Common mechanistic action of bacteriocins from lactic acid bacteria. Appl. Environ. Microbiol. 59, 3003-3010. doi: 10.1128/aem.59.9.3003-3010.1993

Brüssow, H., Canchaya, C., and Hardt, W.-D. (2004). Phages and the evolution of bacterial pathogens: from genomic rearrangements to lysogenic conversion. Microbiol. Mol. Biol. Rev. 68, 560-602. doi: 10.1128/mmbr.68.3.560-602.2004

Buffie, C. G., Jarchum, I., Equinda, M., Lipuma, L., Gobourne, A., Viale, A., et al. (2012). Profound alterations of intestinal microbiota following a single dose of clindamycin results in sustained susceptibility to Clostridium difficile-induced colitis. Infect. Immun. 80, 62-73. doi: 10.1128/iai. 05496-11

Cao, L. T., Wu, J. Q., Xie, F., Hu, S. H., and Mo, Y. (2007). Efficacy of nisin in treatment of clinical mastitis in lactating dairy cows. J. Dairy Sci. 90, 3980-3985. doi: $10.3168 /$ jds.2007-0153 
Capparelli, R., Parlato, M., Borriello, G., Salvatore, P., and Iannelli, D. (2007). Experimental phage therapy against Staphylococcus aureus in mice. Antimicrob. Agents Chemother. 51, 2765-2773. doi: 10.1128/aac.01513-06

Chalekson, C. P., Neumeister, M. W., and Jaynes, J. (2003). Treatment of infected wounds with the antimicrobial peptide D2A21. J. Trauma Acute Care Surg. 54, 770-774. doi: 10.1097/01.ta.0000047047.79701.6d

Chambers, H. F. (2001). The changing epidemiology of Staphylococcus aureus? Emerg. Infect. Dis. 7:178. doi: 10.3201/eid0702.010204

Chan, B. K., Abedon, S. T., and Loc-Carrillo, C. (2013). Phage cocktails and the future of phage therapy. Future Microbiol. 8, 769-783. doi: 10.2217/fmb.13.47

Chatterjee, S., Chatterjee, S., Lad, S. J., Phansalkar, M. S., Rupp, R. H., Ganguli, B. N., et al. (1992). Mersacidin, a new antibiotic from Bacillus. J. Antibiot. 45, 832-838. doi: 10.7164/antibiotics.45.832

Chen, Y.-H., Liu, C.-Y., Lu, J.-J., King, C.-H. R., and Hsueh, P.-R. (2009). In vitro activity of nemonoxacin (TG-873870), a novel non-fluorinated quinolone, against clinical isolates of Staphylococcus aureus, enterococci and Streptococcus pneumoniae with various resistance phenotypes in Taiwan. J. Antimicrob. Chemother. 64, 1226-1229. doi: 10.1093/jac/dkp370

Cheng, M., Zhang, L., Zhang, H., Li, X., Wang, Y., Xia, F., et al. (2018). An ointment consisting of the phage lysin LysGH15 and apigenin for decolonization of methicillin-resistant Staphylococcus aureus from skin wounds. Viruses 10:244. doi: $10.3390 / \mathrm{v} 10050244$

Chhibber, S., Kaur, T., and Kaur, S. (2013). Co-therapy using lytic bacteriophage and linezolid: effective treatment in eliminating methicillin resistant Staphylococcus aureus (MRSA) from diabetic foot infections. PLoS One 8:e56022. doi: 10.1371/journal.pone.0056022

Chi, H. (2018). Garvicin KS, A Bacteriocin with wide Inhibitory Spectrum and Potential Application. Trondheim: Norwegian University of Life Sciences.

Chi, H., and Holo, H. (2018). Synergistic antimicrobial activity between the broad spectrum bacteriocin garvicin KS and nisin, farnesol and polymyxin B against gram-positive and gram-negative bacteria. Curr. Microbiol. 75, 272-277. doi: 10.1007/s00284-017-1375-y

Clokie, M. R., Millard, A. D., Letarov, A. V., and Heaphy, S. (2011). Phages in nature. Bacteriophage 1, 31-45.

Coffey, A., and Ross, R. P. (2002). Bacteriophage-resistance systems in dairy starter strains: molecular analysis to application. Antonie Van Leeuwenhoek 82, 303-321. doi: 10.1007/978-94-017-2029-8_20

Collins, J., Rudkin, J., Recker, M., Pozzi, C., O'gara, J. P., and Massey, R. C. (2010). Offsetting virulence and antibiotic resistance costs by MRSA. ISME J. 4, 577-584. doi: 10.1038/ismej.2009.151

Cotter, P. D., Hill, C., and Ross, R. P. (2005). Bacteriocins: developing innate immunity for food. Nat. Rev. Microbiol. 3, 777-788. doi: 10.1038/nrmicro1273

Cotter, P. D., Ross, R. P., and Hill, C. (2013). Bacteriocins-a viable alternative to antibiotics? Nat. Rev. Microbiol. 11, 95-105. doi: 10.1038/nrmicro2937

Cui, Z., Song, Z., Wang, Y., Zeng, L., Shen, W., Wang, Z., et al. (2012). Complete genome sequence of wide-host-range Staphylococcus aureus phage Jd007. Am. Soc. Microbiol. 86, 13880-13881. doi: 10.1128/jvi.02728-12

da Silva Malheiros, P., Sant'anna, V., De Souza Barbosa, M., Brandelli, A., and De Melo Franco, B. D. G. (2012). Effect of liposome-encapsulated nisin and bacteriocin-like substance P34 on Listeria monocytogenes growth in Minas frescal cheese. Int. J. Food Microbiol. 156, 272-277. doi: 10.1016/j.ijfoodmicro. 2012.04.004

Dajcs, J. J., Hume, E. B. H., Moreau, J. M., Caballero, A. R., Cannon, B. M., and O'Callaghan, R. J. (2000). Lysostaphin treatment of methicillin-resistant Staphylococcus aureus keratitis in the rabbit. Investig. Ophthalmol. Vis. Sci. 41, 1432-1437.

Dakheel, K. H., Rahim, R. A., Neela, V. K., Al-Obaidi, J. R., Hun, T. G., Isa, M. N. M., et al. (2019). Genomic analyses of two novel biofilm-degrading methicillin-resistant Staphylococcus aureus phages. BMC Microbiol. 19:114. doi: 10.1186/s12866-019-1484-9

de Almeida Vaucher, R., Gewehr, C. D. C. V., Correa, A. P. F., Sant'Anna, V., Ferreira, J., and Brandelli, A. (2011). Evaluation of the immunogenicity and in vivo toxicity of the antimicrobial peptide P34. Int. J. Pharm. 421, 94-98. doi: 10.1016/j.ijpharm.2011.09.020

de la Fuente-Núñez, C., Reffuveille, F., Fernández, L., and Hancock, R. E. W. (2013). Bacterial biofilm development as a multicellular adaptation: antibiotic resistance and new therapeutic strategies. Curr. Opin. Microbiol. 16, 580-589. doi: 10.1016/j.mib.2013.06.013
De Maesschalck, V., Gutiérrez, D., Paeshuyse, J., Lavigne, R., and Briers, Y. (2020). Advanced engineering of third-generation lysins and formulation strategies for clinical applications. Crit. Rev. Microbiol 46, 548-564. doi: 10.1080/1040841x. 2020.1809346

de Souza Duarte, A. F., Ceotto-Vigoder, H., Barrias, E. S., Souto-Padrón, T. C. B. S., Nes, I. F., and De Freire Bastos, M. D. C. (2018). Hyicin 4244, the first sactibiotic described in staphylococci, exhibits an anti-staphylococcal biofilm activity. Int. J. Antimicrob. Agents 51, 349-356. doi: 10.1016/j.ijantimicag.2017.06.025

de Vries, J. (2019). An overview: Staphylococcus aureus Phage Therapy. Groningen: University of Groningen.

de Wit, J., Totte, J. E. E., Van Mierlo, M. M. F., Van Veldhuizen, J., Van Doorn, M. B. A., Schuren, F. H. J., et al. (2019). Endolysin treatment against Staphylococcus aureus in adults with atopic dermatitis: a randomized controlled trial. J. Allergy Clin. Immunol. 144:860. doi: 10.1016/j.jaci.2019.05.020

Dobson, A., Cotter, P. D., Ross, R. P., and Hill, C. (2012). Bacteriocin production: a probiotic trait? Appl. Environ. Microbiol. 78, 1-6. doi: 10.1128/aem.05576-11

Dvořáčková, M., RủŽička, F., Benešík, M., Pantůček, R., and DvořákováHeroldová, M. (2019). Antimicrobial effect of commercial phage preparation Stafal ${ }^{\circledR}$ on biofilm and planktonic forms of methicillin-resistant Staphylococcus aureus. Folia Microbiol. 64, 121-126. doi: 10.1007/s12223-018-0622-3

Ekkelenkamp, M. B., Hanssen, M., Danny Hsu, S.-T., De Jong, A., Milatovic, D., Verhoef, J., et al. (2005). Isolation and structural characterization of epilancin 15X, a novel lantibiotic from a clinical strain of Staphylococcus epidermidis. FEBS Lett. 579, 1917-1922. doi: 10.1016/j.febslet.2005.01.083

Ellington, J. K., Harris, M., Hudson, M. C., Vishin, S., Webb, L. X., and Sherertz, R. (2006). Intracellular Staphylococcus aureus and antibiotic resistance: implications for treatment of staphylococcal osteomyelitis. J. Orthop. Res. 24, $87-93$.

Ellis, J.-C., Ross, R. P., and Hill, C. (2019). Nisin Z and lacticin 3147 improve efficacy of antibiotics against clinically significant bacteria. Future Microbiol. 14, 1573-1587. doi: 10.2217/fmb-2019-0153

Enright, M. C., Robinson, D. A., Randle, G., Feil, E. J., Grundmann, H., and Spratt, B. G. (2002). The evolutionary history of methicillin-resistant Staphylococcus aureus (MRSA). Proc. Natl. Acad. Sci. U.S.A. 99, 7687-7692.

Estrella, L. A., Quinones, J., Henry, M., Hannah, R. M., Pope, R. K., Hamilton, T., et al. (2016). Characterization of novel Staphylococcus aureus lytic phage and defining their combinatorial virulence using the OmniLog ${ }^{\circledR}$ system. Bacteriophage 6:e1219440. doi: 10.1080/21597081.2016.1219440

European Centre for Disease Prevention and Control [ECDC] (2014). Antimicrobial Resistance Surveillance in Europe 2014. Stockholm: ECDC. Available online at: https://www.ecdc.europa.eu/en/publications-data/ antimicrobial-resistance-surveillance-europe-2014

Fagundes, P. C., Ceotto, H., Potter, A., De Paiva Brito, M. A. V., Brede, D., Nes, I. F., et al. (2011). Hyicin 3682, a bioactive peptide produced by Staphylococcus hyicus 3682 with potential applications for food preservation. Res. Microbiol. 162, 1052-1059. doi: 10.1016/j.resmic.2011.10.002

Fahim, H. A., Khairalla, A. S., and El-Gendy, A. O. (2016). Nanotechnology: a valuable strategy to improve bacteriocin formulations. Front. Microbiol. 7:1385. doi: $10.3389 /$ fmicb. 2016.01385

Feil, E. J., Cooper, J. E., Grundmann, H., Robinson, D. A., Enright, M. C., Berendt, T., et al. (2003). How clonal is Staphylococcus aureus? J. Bacteriol. 185, 3307-3316.

Fenton, M., Casey, P. G., Hill, C., Gahan, C. G. M., Mcauliffe, O., O'mahony, J., et al. (2010a). The truncated phage lysin CHAPk eliminates Staphylococcus aureus in the nares of mice. Bioeng. Bugs 1, 404-407. doi: 10.4161/bbug.1.6.13422

Fenton, M., Mcauliffe, O., O'mahony, J., and Coffey, A. (2010b). Recombinant bacteriophage lysins as antibacterials. Bioeng. Bugs 1, 9-16. doi: 10.4161/bbug. 1.1.9818

Fernández, L., Delgado, S., Herrero, H., Maldonado, A., and Rodriguez, J. M. (2008). The bacteriocin nisin, an effective agent for the treatment of staphylococcal mastitis during lactation. J. Hum. Lact. 24, 311-316. doi: 10. $1177 / 0890334408317435$

Field, D., Connor, P. M. O., Cotter, P. D., Hill, C., and Ross, R. P. (2008). The generation of nisin variants with enhanced activity against specific grampositive pathogens. Mol. Microbiol. 69, 218-230. doi: 10.1111/j.1365-2958. 2008.06279.x

Field, D., Gaudin, N., Lyons, F., O'connor, P. M., Cotter, P. D., Hill, C., et al. (2015). A bioengineered nisin derivative to control biofilms of Staphylococcus 
pseudintermedius. PLoS One 10:e0119684. doi: 10.1371/journal.pone.01 19684

Field, D., O'connor, R., Cotter, P. D., Ross, R. P., and Hill, C. (2016). In vitro activities of nisin and nisin derivatives alone and in combination with antibiotics against Staphylococcus biofilms. Front. Microbiol. 7:508. doi: 10.3389/ fmicb.2016.00508

Field, D., Quigley, L., O'connor, P. M., Rea, M. C., Daly, K., Cotter, P. D., et al. (2010). Studies with bioengineered Nisin peptides highlight the broad-spectrum potency of Nisin V. Microb. Biotechnol. 3, 473-486. doi: 10.1111/j.1751-7915. 2010.00184.x

Figueiredo, A. M. S., Ferreira, F. A., Beltrame, C. O., and Cortes, M. F. (2017). The role of biofilms in persistent infections and factors involved in ica-independent biofilm development and gene regulation in Staphylococcus aureus. Crit. Rev. Microbiol. 43, 602-620. doi: 10.1080/1040841x.2017.1282941

Fischetti, V. A. (2010). Bacteriophage endolysins: a novel anti-infective to control Gram-positive pathogens. Int. J. Med. Microbiol. 300, 357-362. doi: 10.1016/j. ijmm.2010.04.002

Fish, R., Kutter, E., Wheat, G., Blasdel, B., Kutateladze, M., and Kuhl, S. (2016). Bacteriophage treatment of intransigent diabetic toe ulcers: a case series. J. Wound Care 25, S27-S33.

Flynn, J., Durack, E., Collins, M. N., and Hudson, S. P. (2020). Tuning the strength and swelling of an injectable polysaccharide hydrogel and the subsequent release of a broad spectrum bacteriocin, nisin A. J. Mater. Chem. B 8, 4029-4038. doi: 10.1039/d0tb00169d

Fowler, V. G., Das, A. F., Lipka-Diamond, J., Schuch, R., Pomerantz, R., JáureguiPeredo, L., et al. (2020). Exebacase for patients with Staphylococcus aureus bloodstream infection and endocarditis. J. Clin. Invest. 130, 3750-3760. doi: 10.1172/jci136577

Fraunholz, M., and Sinha, B. (2012). Intracellular Staphylococcus aureus: live-in and let die. Front. Cell. Infect. Microbiol. 2:43. doi: 10.3389/fcimb.2012.00043

Fujiki, J., Nakamura, T., Furusawa, T., Ohno, H., Takahashi, H., Kitana, J., et al. (2018). Characterization of the lytic capability of a LysK-like endolysin, Lys-phisa012, derived from a polyvalent Staphylococcus aureus bacteriophage. Pharmaceuticals 11:25. doi: 10.3390/ph11010025

Garcia, P., Lopez, R., Ronda, C., Garcia, E., and Tomasz, A. (1983). Mechanism of phage-induced lysis in pneumococci. Microbiology 129, 479-487. doi: 10.1099/ 00221287-129-2-479

Gerlach, D., Guo, Y., De Castro, C., Kim, S.-H., Schlatterer, K., Xu, F.-F., et al. (2018). Methicillin-resistant Staphylococcus aureus alters cell wall glycosylation to evade immunity. Nature 563, 705-709. doi: 10.1038/s41586-0180730-x

Gharieb, R. M. A., Saad, M. F., Mohamed, A. S., and Tartor, Y. H. (2020). Characterization of two novel lytic bacteriophages for reducing biofilms of zoonotic multidrug-resistant Staphylococcus aureus and controlling their growth in milk. LWT 124:109145. doi: 10.1016/j.lwt.2020.109145

Gillor, O., Giladi, I., and Riley, M. A. (2009). Persistence of colicinogenic Escherichia coli in the mouse gastrointestinal tract. BMC Microbiol. 9:165. doi: 10.1186/1471-2180-9-165

Gilmer, D. B., Schmitz, J. E., Euler, C. W., and Fischetti, V. A. (2013). Novel bacteriophage lysin with broad lytic activity protects against mixed infection by Streptococcus pyogenes and methicillin-resistant Staphylococcus aureus. Antimicrob. Agents Chemother. 57, 2743-2750. doi: 10.1128/aac.02526-12

Gorski, A., Międzybrodzki, R., Borysowski, J., Dạbrowska, K., Wierzbicki, P., Ohams, M., et al. (2012). Phage as a modulator of immune responses: practical implications for phage therapy. Adv. Virus Res. 83, 41-71.

Götz, F., Perconti, S., Popella, P., Werner, R., and Schlag, M. (2014). Epidermin and gallidermin: staphylococcal lantibiotics. Int. J. Med. Microbiol. 304, 63-71. doi: 10.1016/j.ijmm.2013.08.012

Goudarzi, M., Kobayashi, N., Hashemi, A., Fazeli, M., and Navidinia, M. (2019). Genetic variability of methicillin resistant Staphylococcus aureus strains isolated from burns patients. Osong Public Health Res. Perspect. 10:170. doi: 10.24171/j. phrp.2019.10.3.08

Gradisteanu Pircalabioru, G., Popa, L. I., Marutescu, L., Gheorghe, I., Popa, M., Czobor Barbu, I., et al. (2021). Bacteriocins in the Era of antibiotic resistance: rising to the challenge. Pharmaceutics 13:196. doi: 10.3390/ pharmaceutics 13020196

Gratia, A. (1925). Sur un remarquable exemple d'antagonisme entre deux souches de coilbacille. CR Seances Soc. Biol. Fil. 93, 1040-1041.
Grishin, A. V., Shestak, N. V., Lavrova, N. V., Lyashchuk, A. M., Popova, L. I., Strukova, N. V., et al. (2019). Fusion of lysostaphin to an albumin binding domain prolongs its half-life and bactericidal activity in the systemic circulation. Molecules 24:2892. doi: 10.3390/molecules24162892

Gu, J., Liu, X., Li, Y., Han, W., Lei, L., Yang, Y., et al. (2012). A method for generation phage cocktail with great Ttherapeutic potential. PLoS One 7, e31698. doi: 10.1371/journal.pone.0031698

Gu, J., Xu, W., Lei, L., Huang, J., Feng, X., Sun, C., et al. (2011). LysGH15, a novel bacteriophage lysin, protects a murine bacteremia model efficiently against lethal methicillin-resistant Staphylococcus aureus infection. J. Clin. Microbiol. 49, 111-117. doi: 10.1128/jcm.01144-10

Gutiérrez, D., Rodríguez-Rubio, L., Martínez, B., Rodríguez, A., and García, P. (2016). Bacteriophages as weapons against bacterial biofilms in the food industry. Front. Microbiol. 7:825. doi: 10.3389/fmicb.2016.00825

Haghighat, S., Siadat, S. D., Sorkhabadi, S. M. R., Sepahi, A. A., and Mahdavi, M. (2017). Cloning, expression and purification of autolysin from methicillinresistant Staphylococcus aureus: potency and challenge study in Balb/c mice. Mol. Immunol. 82, 10-18. doi: 10.1016/j.molimm.2016.12.013

Hallajzadeh, M., Mojtahedi, A., Amirmozafari, N., and Pirhajati Mahabadi, V. (2020). Characterizing a lytic bacteriophage infecting methicillin-resistant Staphylococcus aureus (MRSA) isolated from burn patients. Arch. Clin. Infect. Dis. 15:e91634.

Hathaway, H., Ajuebor, J., Stephens, L., Coffey, A., Potter, U., Sutton, J. M., et al. (2017). Thermally triggered release of the bacteriophage endolysin CHAPK and the bacteriocin lysostaphin for the control of methicillin resistant Staphylococcus aureus (MRSA). J. Control. Release 245, 108-115. doi: 10.1016/ j.jconrel.2016.11.030

Healy, B., Field, D., O'connor, P. M., Hill, C., Cotter, P. D., and Ross, R. P. (2013). Intensive mutagenesis of the nisin hinge leads to the rational design of enhanced derivatives. PLoS One 8:e79563. doi: 10.1371/journal.pone.0079563

Heinemann, B., and Williams, R. (1966). Inactivation of nisin by pancreatin. J. Dairy Sci. 49, 312-314. doi: 10.3168/jds.s0022-0302(66)87854-2

Herpers, B. L., Badoux, P., Pietersma, F., Eichenseher, F., and Loessner, M. J. (2016). "Specific lysis of methicillin susceptible, and resistant Staphylococcus aureus by the endolysin staphefekt Sa100"TM", Proceedings of the 24th European Congress of Clinical Microbiology and Infectious Diseases (ECCMID) Barcelona, Spain.

Heunis, T. D. J., Smith, C., and Dicks, L. M. T. (2013). Evaluation of a nisin-eluting nanofiber scaffold to treat Staphylococcus aureus-induced skin infections in mice. Antimicrob. Agents Chemother. 57, 3928-3935. doi: 10.1128/aac.00622-13

Hols, P., Ledesma-García, L., Gabant, P., and Mignolet, J. (2019). Mobilization of microbiota commensals and their bacteriocins for therapeutics. Trends Microbiol. 27, 690-702. doi: 10.1016/j.tim.2019.03.007

Horne, K. C., Howden, B. P., Grabsch, E. A., Graham, M., Ward, P. B., Xie, S., et al. (2009). Prospective comparison of the clinical impacts of heterogeneous vancomycin-intermediate methicillin-resistant Staphylococcus aureus (MRSA) and vancomycin-susceptible MRSA. Antimicrob. Agents Chemother. 53, 34473452. doi: 10.1128/aac.01365-08

Hoskin, D. W., and Ramamoorthy, A. (2008). Studies on anticancer activities of antimicrobial peptides. Biochim. Biophys. Acta Biomembr. 1778, 357-375. doi: 10.1016/j.bbamem.2007.11.008

Hsieh, S.-E., Lo, H.-H., Chen, S.-T., Lee, M.-C., and Tseng, Y.-H. (2011). Wide host range and strong lytic activity of Staphylococcus aureus lytic phage Stau2. Appl. Environ. Microbiol. 77, 756-761. doi: 10.1128/aem.01848-10

$\mathrm{Hu}, \mathrm{X} .-$ Y., Logue, M., and Robinson, N. (2020). Antimicrobial resistance is a global problem-a UK perspective. Eur. J. Integr. Med. 36:101136. doi: 10.1016/j.eujim. 2020.101136

Indiani, C., Sauve, K., Raz, A., Abdelhady, W., Xiong, Y. Q., Cassino, C., et al. (2019). The antistaphylococcal lysin, CF-301, activates key host factors in human blood to potentiate methicillin-resistant Staphylococcus aureus bacteriolysis. Antimicrob. Agents Chemother. 63:e02291-18.

Jang, I.-T., Yang, M., Kim, H.-J., and Park, J.-K. (2020). Novel cytoplasmic bacteriocin compounds derived from Staphylococcus epidermidis selectively kill Staphylococcus aureus, including methicillin-resistant Staphylococcus aureus (MRSA). Pathogens 9:87. doi: 10.3390/pathogens9020087

Jarvis, B., and Mahoney, R. R. (1969). Inactivation of nisin by alpha-chymotrypsin. J. Dairy Sci. 52, 1448-1450. doi: 10.3168/jds.s0022-0302(69)86771-8

Ji, J., Liu, Q., Wang, R., Luo, T., Guo, X., Xu, M., et al. (2020). Identification of a novel phage targeting methicillin-resistant Staphylococcus aureus in vitro 
and in vivo. Microb. Pathog. 149:104317. doi: 10.1016/j.micpath.2020. 104317

Jiang, H., Zou, J., Cheng, H., Fang, J., and Huang, G. (2017). Purification, characterization, and mode of action of pentocin JL-1, a novel bacteriocin isolated from Lactobacillus pentosus, against drug-resistant Staphylococcus aureus. BioMed Res. Int. 2017:7657190.

Jikia, D., Chkhaidze, N., Imedashvili, E., Mgaloblishvili, I., Tsitlanadze, G., Katsarava, R., et al. (2005). The use of a novel biodegradable preparation capable of the sustained release of bacteriophages and ciprofloxacin, in the complex treatment of multidrug-resistant Staphylococcus aureus-infected local radiation injuries caused by exposure to Sr90. Clin. Exp. Dermatol. Clin. Dermatol. 30, 23-26. doi: $10.1111 /$ j.1365-2230.2004.01600.x

Jones, R. N., Mendes, R. E., and Sader, H. S. (2010). Ceftaroline activity against pathogens associated with complicated skin and skin structure infections: results from an international surveillance study. J. Antimicrob. Chemother. 65, iv17-iv31.

Jun, S. Y., Jang, I. J., Yoon, S., Jang, K., Yu, K.-S., Cho, J. Y., et al. (2017). Pharmacokinetics and tolerance of the phage endolysin-based candidate drug Sal200 after a single intravenous administration among healthy volunteers. Antimicrob. Agents Chemother. 61:e02629-16.

Kaneko, J., Narita-Yamada, S., Wakabayashi, Y., and Kamio, Y. (2009). Identification of ORF636 in phage $\varphi$ SLT carrying Panton-Valentine leukocidin genes, acting as an adhesion protein for a poly (glycerophosphate) chain of lipoteichoic acid on the cell surface of Staphylococcus aureus. J. Bacteriol. 191, 4674-4680. doi: 10.1128/jb.01793-08

Karau, M. J., Schmidt-Malan, S. M., Yan, Q., Greenwood-Quaintance, K. E., Mandrekar, J., Lehoux, D., et al. (2019). Exebacase in addition to daptomycin is more active than daptomycin or exebacase alone in methicillin-resistant Staphylococcus aureus osteomyelitis in rats. Antimicrob. Agents Chemother. 63:e01235-19.

Kaur, S., Harjai, K., and Chhibber, S. (2012). Plaque-size enhancement of Mrsa phages using sub-lethal concentrations of antibiotics. Appl. Environ. Microbiol. 17:e02371-12.

Keary, R., Mcauliffe, O., Ross, R. P., Hill, C., O’mahony, J., and Coffey, A. (2014). Genome analysis of the staphylococcal temperate phage DW2 and functional studies on the endolysin and tail hydrolase. Bacteriophage 4:e28451. doi: 10. 4161/bact.28451

Kellner, R., Jung, G., Hörner, T., Zähner, H., Schnell, N., Entian, K. D., et al. (1988). Gallidermin: a new lanthionine-containing polypeptide antibiotic. Eur. J. Biochem. 177, 53-59. doi: 10.1111/j.1432-1033.1988.tb14344.x

Kelly, D., Mcauliffe, O., Ross, R. P., and Coffey, A. (2012). Prevention of Staphylococcus aureus biofilm formation and reduction in established biofilm density using a combination of phage $\mathrm{K}$ and modified derivatives. Lett. Appl. Microbiol. 54, 286-291. doi: 10.1111/j.1472-765x.2012.03205.x

Kempf, M., Theobald, U., and Fiedler, H.-P. (2001). "The antibiotic galliderminevolution of a production process," in Novel Frontiers in the Production of Compounds for Biomedical Use, eds J. Anné, F. Shapiro, A. van Broekhoven (Cham: Springer).

Kitching, M., Mathur, H., Flynn, J., Byrne, N., Dillon, P., Sayers, R., et al. (2019). A live bio-therapeutic for mastitis, containing Lactococcus lactis Dpc3147 with comparable efficacy to antibiotic treatment. Front. Microbiol. 10:2220. doi: 10. 3389/fmicb.2019.02220

Klaenhammer, T. R. (1988). Bacteriocins of lactic acid bacteria. Biochimie 70, 337-349.

Klostermann, K., Crispie, F., Flynn, J., Meaney, W., Ross, R. P., and Hill, C. (2010). Efficacy of a teat dip containing the bacteriocin lacticin 3147 to eliminate Grampositive pathogens associated with bovine mastitis. J. Dairy Res. 77, 231-238. doi: 10.1017/s0022029909990239

Kortright, K. E., Chan, B. K., Koff, J. L., and Turner, P. E. (2019). Phage therapy: a renewed approach to combat antibiotic-resistant bacteria. Cell Host Microbe 25, 219-232. doi: 10.1016/j.chom.2019.01.014

Kruszewska, D., Sahl, H.-G., Bierbaum, G., Pag, U., Hynes, S. O., and Ljungh, $\AA$ (2004). Mersacidin eradicates methicillin-resistant Staphylococcus aureus (MRSA) in a mouse rhinitis model. J. Antimicrob. Chemother. 54, 648-653. doi: $10.1093 / \mathrm{jac} / \mathrm{dkh} 387$

Kumaran, D., Taha, M., Yi, Q., Ramirez-Arcos, S., Diallo, J.-S., Carli, A., et al. (2018). Does treatment order matter? Investigating the ability of bacteriophage to augment antibiotic activity against Staphylococcus aureus biofilms. Front. Microbiol. 9:127. doi: 10.3389/fmicb.2018.00127

Labrie, S. J., Samson, J. E., and Moineau, S. (2010). Bacteriophage resistance mechanisms. Nat. Rev. Microbiol. 8:317. doi: 10.1038/nrmicro2315

LaPlante, K. L. (2007). In vitro activity of lysostaphin, mupirocin, and tea tree oil against clinical methicillin-resistant Staphylococcus aureus. Diagn. Microbiol. Infect. Dis. 57, 413-418. doi: 10.1016/j.diagmicrobio.2006.09.007

Leimer, N., Rachmühl, C., Palheiros Marques, M., Bahlmann, A. S., Furrer, A., Eichenseher, F., et al. (2016). Nonstable Staphylococcus aureus small-colony variants are induced by low $\mathrm{pH}$ and sensitized to antimicrobial therapy by phagolysosomal alkalinization. J. Infect. Dis. 213, 305-313. doi: 10.1093/infdis/ jiv388

Lenski, R. E. (1988). Dynamics of Interactions Between Bacteria and Virulent Bacteriophage. Advances in Microbial Ecology. Berlin: Springer.

León, M., and Bastías, R. (2015). Virulence reduction in bacteriophage resistant bacteria. Front. Microbiol. 6:343. doi: 10.3389/fmicb.2015.00343

Li, X., Gerlach, D., Du, X., Larsen, J., Stegger, M., Kühner, P., et al. (2015). An accessory wall teichoic acid glycosyltransferase protects Staphylococcus aureus from the lytic activity of Podoviridae. Sci. Rep. 5, 1-10.

Li, X., Hu, T., Wei, J., He, Y., Abdalla, A. E., Wang, G., et al. (2021). Characterization of a novel bacteriophage Henu2 and evaluation of the synergistic antibacterial activity of phage-antibiotics. Antibiotics 10:174. doi: 10.3390/antibiotics 10020174

Lin, D. M., Koskella, B., and Lin, H. C. (2017). Phage therapy: an alternative to antibiotics in the age of multi-drug resistance. World J. Gastrointest. Pharmacol. Ther. 8:162. doi: 10.4292/wjgpt.v8.i3.162

Lindsay, J. A. (2010). Genomic variation and evolution of Staphylococcus aureus. Int. J. Med. Microbiol. 300, 98-103. doi: 10.1016/j.ijmm.2009.08.013

Lindsay, J. A., Knight, G. M., Budd, E. L., and Mccarthy, A. J. (2012). Shuffling of mobile genetic elements (MGEs) in successful healthcare-associated MRSA (HA-MRSA). Mob. Genet. Elements 2, 239-243. doi: 10.4161/mge.22085

Liu, H., Gao, Y., Yu, L.-R., Jones, R. C., Elkins, C. A., and Hart, M. E. (2011). Inhibition of Staphylococcus aureus by lysostaphin-expressing Lactobacillus plantarum WCFS1 in a modified genital tract secretion medium. Appl. Environ. Microbiol. 77, 8500-8508. doi: 10.1128/aem.06755-11

Loeffler, J. M., Nelson, D., and Fischetti, V. A. (2001). Rapid killing of Streptococcus pneumoniae with a bacteriophage cell wall hydrolase. Science 294, 2170-2172. doi: $10.1126 /$ science. 1066869

Loessner, M. J. (2005). Bacteriophage endolysins-current state of research and applications. Curr. Opin. Microbiol. 8, 480-487. doi: 10.1016/j.mib.2005.06.002

Lowy, F. D. (1998). Staphylococcus aureus infections. New Engl. J. Med. 339, 520-532.

Manosroi, A., Khanrin, P., Lohcharoenkal, W., Werner, R. G., Götz, F., Manosroi, W., et al. (2010). Transdermal absorption enhancement through rat skin of gallidermin loaded in niosomes. Int. J. Pharm. 392, 304-310. doi: 10.1016/j. ijpharm.2010.03.064

Mantovani, H. C., and Russell, J. B. (2001). Nisin resistance of Streptococcus bovis. Appl. Environ. Microbiol. 67, 808-813. doi: 10.1128/aem.67.2.808-813.2001

Mathur, H., Field, D., Rea, M. C., Cotter, P. D., Hill, C., and Ross, R. P. (2017). Bacteriocin-antimicrobial synergy: a medical and food perspective. Front. Microbiol. 8:1205. doi: 10.3389/fmicb.2017.01205

Matsuzaki, S., Yasuda, M., Nishikawa, H., Kuroda, M., Ujihara, T., Shuin, T., et al. (2003). Experimental protection of mice against lethal Staphylococcus aureus infection by novel bacteriophage $\varphi$ MR11. J. Infect. Dis. 187, 613-624.

McCallin, S., Sacher, J. C., Zheng, J., and Chan, B. K. (2019). Current state of compassionate phage therapy. Viruses 11:343. doi: 10.3390/v11040343

McCormick, J. K., Yarwood, J. M., and Schlievert, P. M. (2001). Toxic shock syndrome and bacterial superantigens: an update. Annu. Rev. Microbiol. 55, 77-104. doi: 10.1146/annurev.micro.55.1.77

Meade, E., Slattery, M. A., and Garvey, M. (2020). Bacteriocins, potent antimicrobial peptides and the fight against multi drug resistant species: resistance is futile? Antibiotics 9:32. doi: 10.3390/antibiotics9010032

Melo, L. D. R., Brandão, A., Akturk, E., Santos, S. B., and Azeredo, J. (2018). Characterization of a new Staphylococcus aureus Kayvirus harboring a lysin active against biofilms. Viruses 10:182.

Mendes, R. E., Sader, H. S., Flamm, R. K., Farrell, D. J., and Jones, R. N. (2014). Oritavancin activity against Staphylococcus aureus causing invasive infections 
in Us and European hospitals: a 5-year international surveillance program. Antimicrob. Agents Chemother. 58, 2921-2924.

Meredith, T. C., Swoboda, J. G., and Walker, S. (2008). Late-stage polyribitol phosphate wall teichoic acid biosynthesis in Staphylococcus aureus. J. Bacteriol. 190, 3046-3056.

Modi, S. R., Lee, H. H., Spina, C. S., and Collins, J. J. (2013). Antibiotic treatment expands the resistance reservoir and ecological network of the phage metagenome. Nature 499, 219-222.

Nakamura, T., Kitana, J., Fujiki, J., Takase, M., Iyori, K., Simoike, K., et al. (2020). Lytic activity of polyvalent staphylococcal bacteriophage PhiSA012 and its endolysin Lys-PhiSA012 against antibiotic-resistant staphylococcal clinical isolates from canine skin infection sites. Front. Med. 7, 234. doi: 10.3389/fmed. 2020.00234

Navaratna, M. A. D. B., Sahl, H.-G., and Tagg, J. R. (1998). Two-component anti-Staphylococcus aureus lantibiotic activity produced by Staphylococcus aureusC55. Appl. Environ. Microbiol. 64, 4803-4808.

Netz, D. J. A., Pohl, R., Beck-Sickinger, A. G., Selmer, T., Pierik, A. J., De Freire Bastos, M. D. C., et al. (2002). Biochemical characterisation and genetic analysis of aureocin A53, a new, atypical bacteriocin from Staphylococcus aureus. J. Mol. Biol. 319, 745-756.

Newstead, L. L., Varjonen, K., Nuttall, T., and Paterson, G. K. (2020). Staphylococcal-produced bacteriocins and antimicrobial peptides: their potential as alternative treatments for Staphylococcus aureus infections. Antibiotics 9:40.

Nilebäck, L., Widhe, M., Seijsing, J., Bysell, H., Sharma, P. K., and Hedhammar, M. (2019). Bioactive silk coatings reduce the adhesion of Staphylococcus aureus while supporting growth of osteoblast-like cells. ACS Appl. Mater. Interf. 11, 24999-25007.

Nissen-Meyer, J., Rogne, P., Oppegard, C., Haugen, H. S., and Kristiansen, P. E. (2009). Structure-function relationships of the non-lanthionine-containing peptide (class II) bacteriocins produced by gram-positive bacteria. Curr. Pharm. Biotechnol. 10, 19-37.

Odah, K. A., Dong, W.-L., Lei, L., Atiah, L. A., Wang, Y.-M., Kong, L.C., et al. (2019). Isolation, identification, and characterization of a novel bacteriocin produced by brevibacillus laterosporus DS-3 against methicillinresistant staphylococcus aureus (MRSA). Int. J. Pept. Res. Ther. 26, 709-715. doi: 10.1007/s10989-019-09878-4

O’Flaherty, S., Coffey, A., Edwards, R., Meaney, W., Fitzgerald, G. F., and Ross, R. P. (2004). Genome of staphylococcal phage K: a new lineage of Myoviridae infecting gram-positive bacteria with a low G+ C content. J. Bacteriol. 186, 2862-2871.

O'Flaherty, S., Ross, R. P., and Coffey, A. (2009). Bacteriophage and their lysins for elimination of infectious bacteria. FEMS Microbiol. Rev. 33, 801-819.

O’Flaherty, S., Ross, R. P., Meaney, W., Fitzgerald, G. F., Elbreki, M. F., and Coffey, A. (2005). Potential of the polyvalent anti-Staphylococcus bacteriophage $\mathrm{K}$ for control of antibiotic-resistant staphylococci from hospitals. Appl. Environ. Microbiol. 71, 1836-1842.

Okuda, K.-I., Zendo, T., Sugimoto, S., Iwase, T., Tajima, A., Yamada, S., et al. (2013). Effects of bacteriocins on methicillin-resistant Staphylococcus aureus biofilm. Antimicrob. Agents Chemother. 57, 5572-5579.

Ooi, M. L., Drilling, A. J., Morales, S., Fong, S., Moraitis, S., Macias-Valle, L., et al. (2019). Safety and tolerability of bacteriophage therapy for chronic rhinosinusitis due to Staphylococcus aureus. JAMA Otolaryngol. Head Neck Surg. 145, 723-729.

Oppedijk, S. F. (2017). Identification, Purification and Elucidation of the Mode of Action of (Novel) Antimicrobial Substances. Utrecht: Utrecht University.

O’Shea, E. F., O'connor, P. M., O’sullivan, O., Cotter, P. D., Ross, R. P., and Hill, C. (2013). Bactofencin A, a new type of cationic bacteriocin with unusual immunity. mBio 4:e00498-13.

O’Sullivan, J. N., O'connor, P. M., Rea, M. C., O'sullivan, O., Walsh, C. J., Healy, B., et al. (2019). Nisin J, a novel natural nisin variant, is produced by Staphylococcus capitis sourced from the human skin microbiota. J. Bacteriol. 202:e00639-19.

Otto, M. (2012). Mrsa virulence and spread. Cell Microbiol. 14, 15131521.

Ovchinnikov, K. V., Kranjec, C., Thorstensen, T., Carlsen, H., and Diep, D. B. (2020). Successful development of bacteriocins into therapeutic formulation for treatment of MRSA skin infection in a murine model. Antimicrob. Agents Chemother. 64:e00829-20.
Paik, S. H., Chakicherla, A., and Hansen, J. N. (1998). Identification and characterization of the structural and transporter genes for, and the chemical and biological properties of, sublancin 168, a novel lantibiotic produced by Bacillus subtilis 168. J. Biol. Chem. 273, 23134-23142.

Pantucek, R., Petras, P., Doskar, J., Ruzickova, V., Bostik, J., and Mosa, M. (2013). Comparison of In Vitro Lytic Activities of Three Bacteriophage Preparations Stafal ${ }^{\circledR}$, Staphylon ${ }^{\circledR}$, and Pyobacteriophagum Liquidum Against Methicillin Resistant Staphylococcus aureus. Ulyanovsk: УГСХА им. ПА Столыпина.

Pantůček, R., Rosypalová, A., Doškař, J., Kailerová, J., RùŽičková, V., Borecká, P., et al. (1998). The polyvalent staphylococcal phage $\varphi 812$ : its host-range mutants and related phages. Virology 246, 241-252.

Pasberg-Gauhl, C. (2014). A need for new generation antibiotics against MRSA resistant bacteria. Drug Discov. Today Technol. 11, 109-116.

Peng, C., Hanawa, T., Azam, A. H., Leblanc, C., Ung, P., Matsuda, T., et al. (2019). Silviavirus phage $\varphi \mathrm{MR} 003$ displays a broad host range against methicillinresistant Staphylococcus aureus of human origin. Appl. Microbiol. Biotechnol. $103,7751-7765$.

Pertics, B. Z., Szénásy, D., Dunai, D., Born, Y., Fieseler, L., Kovács, T., et al. (2020). Isolation of a novel lytic bacteriophage against a nosocomial methicillin-resistant Staphylococcus aureus belonging to St45. BioMed Res. Int. 2020:5463801.

Peyrusson, F., Varet, H., Nguyen, T. K., Legendre, R., Sismeiro, O., Coppée, J.Y., et al. (2020). Intracellular Staphylococcus aureus persisters upon antibiotic exposure. Nat. Commun. 11, 1-14.

Pieta, P., Majewska, M., Su, Z., Grossutti, M., Wladyka, B., Piejko, M., et al. (2016). Physicochemical studies on orientation and conformation of a new bacteriocin BacSp222 in a planar phospholipid bilayer. Langmuir 32, 56535662 .

Piper, C., Draper, L. A., Cotter, P. D., Ross, R. P., and Hill, C. (2009). A comparison of the activities of lacticin 3147 and nisin against drug-resistant Staphylococcus aureus and Enterococcus species. J. Antimicrob. Chemother. 64, 546-551.

Pollack, J. H., and Neuhaus, F. C. (1994). Changes in wall teichoic acid during the rod-sphere transition of Bacillus subtilis 168. J. Bacteriol. 176, 7252-7259.

Queck, S. Y., Khan, B. A., Wang, R., Bach, T.-H. L., Kretschmer, D., Chen, L., et al. (2009). Mobile genetic element-encoded cytolysin connects virulence to methicillin resistance in MRSA. PLoS Pathog. 5:e1000533. doi: 10.1371/journal. ppat. 1000533

Rahimzadeh, G., Gill, P., Saeedi, M., Ghasemi, M., Rokni, G. R., Rostamkalaei, S. S., et al. (2020). Evaluation of bacteriophage products against burn wound Methicillin-resistant Staphylococcus aureus (MRSA) infections. Wound Med. 28:100182.

Rashel, M., Uchiyama, J., Ujihara, T., Uehara, Y., Kuramoto, S., Sugihara, S., et al. (2007). Efficient elimination of multidrug-resistant Staphylococcus aureus by cloned lysin derived from bacteriophage pmr11. J. Infect. Dis. 196, 12371247.

Rea, M. C., Alemayehu, D., Casey, P. G., O'connor, P. M., Lawlor, P. G., Walsh, M., et al. (2014). Bioavailability of the anti-clostridial bacteriocin thuricin $\mathrm{Cd}$ in gastrointestinal tract. Microbiology 160, 439-445.

Riley, M. A., and Wertz, J. E. (2002). Bacteriocin diversity: ecological and evolutionary perspectives. Biochimie 84, 357-364.

Röhrig, C., Huemer, M., Lorgé, D., Luterbacher, S., Phothaworn, P., Schefer, C., et al. (2020). Targeting hidden pathogens: cell-penetrating enzybiotics eradicate intracellular drug-resistant Staphylococcus aureus. mBio 11: e00209-20.

Royer, S., Morais, A. P., Da Fonseca, and Batistão, D. W. (2021). Phage therapy as strategy to face post-antibiotic era: a guide to beginners and experts. Arch. Microbiol. [Epub ahead of print].

Ryan, C., Gúeret, C., Berry, D., Corcoran, M., Keane, M. T., and Mac Namee, B. (2021). Predicting illness for a sustainable dairy agriculture: predicting and explaining the onset of mastitis in dairy cows. arXiv preprint arXiv:2101.02188.

Saising, J., Dube, L., Ziebandt, A.-K., Voravuthikunchai, S. P., Nega, M., and Götz, F. (2012). Activity of gallidermin on Staphylococcus aureus and Staphylococcus epidermidis biofilms. Antimicrob. Agents Chemother. 56, 5804-5810.

Salmond, G. P. C., and Fineran, P. C. (2015). A century of the phage: past, present and future. Nat. Rev. Microbiol. 13:777.

Sandiford, S., and Upton, M. (2012). Identification, characterization, and recombinant expression of epidermicin NI01, a novel unmodified 
bacteriocin produced by Staphylococcus epidermidis that displays potent activity against Staphylococci. Antimicrob. Agents Chemother. 56, 15391547.

Schindler, C. A., and Schuhardt, V. T. (1965). Purification and properties of lysostaphin-a lytic agent for Staphylococcus aureus. Biochim. Biophys. Acta Gen. Subj. 97, 242-250.

Schmelcher, M., and Loessner, M. J. (2021). Bacteriophage endolysins-extending their application to tissues and the bloodstream. Curr. Opin. Biotechnol. 68, 51-59.

Schnell, N., Entian, K.-D., Schneider, U., Götz, F., Zähner, H., Kellner, R., et al. (1988). Prepeptide sequence of epidermin, a ribosomally synthesized antibiotic with four sulphide-rings. Nature 333, 276-278.

Schuch, R., Khan, B. K., Raz, A., Rotolo, J. A., and Wittekind, M. (2017). Bacteriophage lysin CF-301, a potent antistaphylococcal biofilm agent. Antimicrob. Agents Chemother. 61:e02666-16.

Seil, J. T., and Webster, T. J. (2012). Antimicrobial applications of nanotechnology: methods and literature. Int. J. Nanomed. 7:2767.

Shetru, M. N., Karched, M., and Agsar, D. (2021). Locally isolated broad host-range bacteriophage kills methicillin-resistant Staphylococcus aureus in an in vivo skin excisional wound model in mice. Microb. Pathog. 152:104744.

Smith, J. R., Roberts, K. D., and Rybak, M. J. (2015). Dalbavancin: a novel lipoglycopeptide antibiotic with extended activity against Gram-positive infections. Infect. Dis., Ther. 4, 245-258.

Soltani, S., Hammami, R., Cotter, P. D., Rebuffat, S., Said, L. B., Gaudreau, H., et al. (2021). Bacteriocins as a new generation of antimicrobials: toxicity aspects and regulations. FEMS Microbiol. Rev. 45:fuaa039.

Son, B., Kong, M., Lee, Y., and Ryu, S. (2021). Development of a novel chimeric endolysin, Lys109 with enhanced lytic activity against Staphylococcus aureus. Front. Microbiol. 11:615887. doi: 10.3389/fmicb.2020.615887

Son, J.-S., Lee, S.-J., Jun, S. Y., Yoon, S. J., Kang, S. H., Paik, H. R., et al. (2010). Antibacterial and biofilm removal activity of a podoviridae Staphylococcus aureus bacteriophage SAP-2 and a derived recombinant cell-wall-degrading enzyme. Appl. Microbiol. Biotechnol. 86, 1439-1449.

Soong, G., Paulino, F., Wachtel, S., Parker, D., Wickersham, M., Zhang, D., et al. (2015). Methicillin-resistant Staphylococcus aureus adaptation to human keratinocytes. mBio 6:e00289-15.

Sugai, M., Fujiwara, T., Akiyama, T., Ohara, M., Komatsuzawa, H., Inoue, S., et al. (1997). Purification and molecular characterization of glycylglycine endopeptidase produced by Staphylococcus capitis EPK1. J. Bacteriol. 179, 1193-1202.

Sulthana, R., and Archer, A. C. (2020). Bacteriocin nanoconjugates: boon to medical and food industry. J. Appl. Microbiol. [Epub ahead of print].

Sung, C., Kim, B. G., Kim, S., Joo, H. S., and Kim, P. I. (2010). Probiotic potential of Staphylococcus hominis MBBL 2-9 as anti-Staphylococcus aureus agent isolated from the vaginal microbiota of a healthy woman. J. Appl. Microbiol. 108, 908-916.

Sybesma, W., Rohde, C., Bardy, P., Pirnay, J.-P., Cooper, I., Caplin, J., et al. (2018). Silk route to the acceptance and re-implementation of bacteriophage therapy-part Ii. Antibiotics 7:35.

Tanji, Y., Shimada, T., Yoichi, M., Miyanaga, K., Hori, K., and Unno, H. (2004). Toward rational control of Escherichia coli O157: H7 by a phage cocktail. Appl. Microbiol. Biotechnol. 64, 270-274.

Tiemersma, E. W., Bronzwaer, S. L. A. M., Lyytikäinen, O., Degener, J. E., Schrijnemakers, P., Bruinsma, N., et al. (2004). Methicillin-resistant Staphylococcus aureus in Europe, 1999-2002. Emerg. Infect. Dis. 10:1627.

Tkhilaishvili, T., Lombardi, L., Klatt, A.-B., Trampuz, A., and Di Luca, M. (2018). Bacteriophage Sb-1 enhances antibiotic activity against biofilm, degrades exopolysaccharide matrix and targets persisters of Staphylococcus aureus. Int. J. Antimicrob. Agents 52, 842-853.

Totte, J. E. E., Van Doorn, M. B., and Pasmans, S. G. M. A. (2017). Successful treatment of chronic Staphylococcus aureus-related dermatoses with the topical endolysin Staphefekt SA. 100: a report of 3 cases. Case Rep. Dermatol. 9, $19-25$.

Traber, K. E., Lee, E., Benson, S., Corrigan, R., Cantera, M., Shopsin, B., et al. (2008). agr function in clinical Staphylococcus aureus isolates. Microbiology 154: 2265.

Turecek, P. L., Bossard, M. J., Schoetens, F., and Ivens, I. A. (2016). PEGylation of biopharmaceuticals: a review of chemistry and nonclinical safety information of approved drugs. J. Pharm. Sci. 105, 460-475. doi: 10.1016/j.xphs.2015.11.015
Van Schaik, W., Gahan, C. G. M., and Hill, C. (1999). Acid-adapted Listeria monocytogenes displays enhanced tolerance against the lantibiotics nisin and lacticin 3147. J. Food Prot. 62, 536-540.

Vandenesch, F., Naimi, T., Enright, M. C., Lina, G., Nimmo, G. R., Heffernan, H., et al. (2003). Community-acquired methicillin-resistant Staphylococcus aureus carrying Panton-Valentine leukocidin genes: worldwide emergence. Emerg. Infect. Dis. 9:978.

Vandersteegen, K., Mattheus, W., Ceyssens, P.-J., Bilocq, F., De Vos, D., Pirnay, J.-P., et al. (2011). Microbiological and molecular assessment of bacteriophage Isp for the control of Staphylococcus aureus. PLoS One 6:e24418. doi: 10.1371/ journal.pone.0024418

Velásquez, J. E., Zhang, X., and Van Der Donk, W. A. (2011). Biosynthesis of the antimicrobial peptide epilancin 15X and its N-terminal lactate. Chem. Biol. 18, 857-867.

Walsh, S., Shah, A., and Mond, J. (2003). Improved pharmacokinetics and reduced antibody reactivity of lysostaphin conjugated to polyethylene glycol. Antimicrob. Agents Chemother. 47, 554-558.

Wang, S., Wang, Q., Zeng, X., Ye, Q., Huang, S., Yu, H., et al. (2017). Use of the antimicrobial peptide sublancin with combined antibacterial and immunomodulatory activities to protect against methicillin-resistant Staphylococcus aureus infection in mice. J. Agric. Food Chem. 65, 85958605 .

Wang, Z., Kong, L., Liu, Y., Fu, Q., Cui, Z., Wang, J., et al. (2018). A phage lysin fused to a cell-penetrating peptide kills intracellular methicillinresistant Staphylococcus aureus in keratinocytes and has potential as a treatment for skin infections in mice. Appl. Environ. Microbiol. 84:e00 $380-18$.

Watson, A., Sauve, K., Cassino, C., and Schuch, R. (2020). Exebacase demonstrates in vitro synergy with a broad range of antibiotics against both methicillinresistant and methicillin-susceptible Staphylococcus aureus. Antimicrob. Agents Chemother. 64:e01885-19. doi: 10.1128/AAC.01885-19

Weiner-Lastinger, L. M., Abner, S., Edwards, J. R., Kallen, A. J., Karlsson, M., Magill, S. S., et al. (2020). Antimicrobial-resistant pathogens associated with adult healthcare-associated infections: summary of data reported to the National Healthcare Safety Network, 2015-2017. Infect. Control Hosp. Epidemiol. 41, $1-18$.

Wiedemann, I., Böttiger, T., Bonelli, R. R., Wiese, A., Hagge, S. O., Gutsmann, T., et al. (2006). The mode of action of the lantibiotic lacticin 3147-a complex mechanism involving specific interaction of two peptides and the cell wall precursor lipid II. Mol. Microbiol. 61, 285-296.

Wittebole, X., De Roock, S., and Opal, S. M. (2014). A historical overview of bacteriophage therapy as an alternative to antibiotics for the treatment of bacterial pathogens. Virulence 5, 226-235.

Wladyka, B., Piejko, M., Bzowska, M., Pieta, P., Krzysik, M., Mazurek, Ł, et al. (2015). A peptide factor secreted by Staphylococcus pseudintermedius exhibits properties of both bacteriocins and virulence factors. Sci. Rep. 5: 14569.

Wu, J., Hu, S., and Cao, L. (2007). Therapeutic effect of nisin $\mathrm{Z}$ on subclinical mastitis in lactating cows. Antimicrob. Agents Chemother. 51, 3131-3135.

Xia, G., Corrigan, R. M., Winstel, V., Goerke, C., Gründling, A., and Peschel, A. (2011). Wall teichoic acid-dependent adsorption of staphylococcal siphovirus and myovirus. J. Bacteriol. 193, 4006-4009.

Xia, G., Maier, L., Sanchez-Carballo, P., Li, M., Otto, M., Holst, O., et al. (2010). Glycosylation of wall teichoic acid in Staphylococcus aureus by TarM. J. Biol. Chem. 285, 13405-13415.

Zohri, M., Shafiee Alavidjeh, M., Mirdamadi, S. S., Behmadi, H., Hossaini Nasr, S. M., Eshghi Gonbaki, S., et al. (2013). Nisin-loaded chitosan/alginate nanoparticles: a hopeful hybrid biopreservative. J. Food Saf. 33, 40-49.

Conflict of Interest: The authors declare that the research was conducted in the absence of any commercial or financial relationships that could be construed as a potential conflict of interest.

Copyright (C) 2021 Walsh, Johnson, Hill and Ross. This is an open-access article distributed under the terms of the Creative Commons Attribution License (CC BY). The use, distribution or reproduction in other forums is permitted, provided the original author(s) and the copyright owner(s) are credited and that the original publication in this journal is cited, in accordance with accepted academic practice. No use, distribution or reproduction is permitted which does not comply with these terms. 